\title{
The Morphologies of the Semiconductor Oxides and Their Gas-Sensing Properties
}

\author{
Tingting Lin ${ }^{1,2} \mathbb{B}^{1}$, Xin Lv ${ }^{1,2}$, Shuang $\mathrm{Li}^{1,2}$ and Qingji Wang ${ }^{1,2, *}$ \\ 1 College of Instrumentation and Electrical Engineering, Jilin University, Changchun 130061, China; \\ ttlin@jlu.edu.cn (T.L.); xinlv15@mails.jlu.edu.cn (X.L.); shuangli16@mails.jlu.edu.cn (S.L.) \\ 2 Key Laboratory of Geophysics Exploration Equipment, Ministry of Education of China, \\ Changchun 130061, China \\ * Correspondence: wangqingji@jlu.edu.cn; Tel.: +86-151-0445-5386
}

Received: 19 October 2017; Accepted: 28 November 2017; Published: 30 November 2017

\begin{abstract}
Semiconductor oxide chemoresistive gas sensors are widely used for detecting deleterious gases due to low cost, simple preparation, rapid response and high sensitivity. The performance of gas sensor is greatly affected by the morphology of the semiconductor oxide. There are many semiconductor oxide morphologies, including zero-dimensional, one-dimensional, two-dimensional and three-dimensional ones. The semiconductor oxides with different morphologies significantly enhance the gas-sensing performance. Among the various morphologies, hollow nanostructures and core-shell nanostructures are always the focus of research in the field of gas sensors due to their distinctive structural characteristics and superior performance. Herein the morphologies of semiconductor oxides and their gas-sensing properties are reviewed. This review also proposes a potential strategy for the enhancement of gas-sensing performance in the future.
\end{abstract}

Keywords: morphology; nanostructure; semiconductor; oxide; gas sensor

\section{Introduction}

In recent years, the issue of environmental safety has attracted much attention with rapid economic development [1-4]. The activities in our everyday life result in the release of many deleterious gases, such as $\mathrm{H}_{2} \mathrm{~S}$ [5], $\mathrm{NO}_{2}$ [6], $\mathrm{CO}$ [7], $\mathrm{HCHO}$ [8], $\mathrm{H}_{2}$ [9], $\mathrm{NH}_{3}$ [10], $\mathrm{CO}_{2}$ [11], $\mathrm{C}_{2} \mathrm{H}_{2}$ [12], $\mathrm{C}_{2} \mathrm{H}_{5} \mathrm{OH}$ [13], etc. It is not merely that these gases harm people's health, but they also restrict sustainable development in the current situation. In order to effectively detect various gases, many researchers have tried to develop different kinds of gas sensors. Among the numerous gas sensors, semiconductor oxide gas sensors have received great attention owing to their high selectivity and sensitivity, and fast response for monitoring hazardous gases.

As we all know, the sensing material is the core component of semiconductor oxide gas sensors, and the morphologies of semiconductor oxides have a critical influence on the gas-sensing performance of sensors. The gas-sensing performance is determined by the reaction rate and amount of oxygen species in the redox reaction, which depend on the microstructure, shape and size of the semiconductor oxide used. In addition, the sensing process occurs on the different sites of the sensing material and thus the performance is related to the morphology. Furthermore, different morphologies have different advantages, contributing to increased surface active sites, accelerated response speeds and enhanced gas diffusion.

Many researchers have attempted to fabricate novel nanostructures to improve the performance of sensors [14,15]. Various semiconductor oxide morphologies have been prepared, including nanoparticles [16], nanowires [17], nanofibers [18], nanosheets [19], nanoflowers [20], hollow [21] and core-shell [22] nanostructures, etc. These semiconductor oxides are commonly prepared by 
two methods: top-down techniques and the bottom-up techniques. In the top-down techniques, the specific size and morphology of nanomaterials can be obtained from larger or bulk solids. By contrast, the bottom-up techniques construct nanostructures through crystal growth and self-assembled units. So far, many reviews about semiconductor oxide gas sensors have been published [23-26]. Nevertheless, the relation between the morphology of semiconducting oxide and the gas-sensing performance of the sensor using them are not clearly established yet. Therefore, the understanding of favorable morphologies and the parameters of the microstructure at the interaction with gases are important for further improvement of gas sensors. In this review, we provide an overview of semiconductor oxides with different morphologies with gas-sensing properties, with the expectation of providing potential guidelines for identifying morphology characteristics that at beneficial for sensing performance.

\section{Gas-Sensing Mechanism}

To better design novel semiconductor oxide morphologies and improve the gas-sensing performances of sensors, it is necessary to clarify the gas-sensing mechanism. As we all know, the working principle of gas sensors is based on the change in resistance of the sensor on exposure to a target gas. However, the gas-sensing mechanism details are still disputed. This review will present five aspects to understand the gas-sensing mechanism, including the adsorption of oxygen on the surface of semiconductor oxides, band gap, Schottky barrier contact, the catalysis-based sensing mechanism and the heterojunction-based sensing mechanism.

\subsection{Adsorption Oxygen on the Surface of Semiconductor Oxides}

The adsorption reactions occur on the surface of semiconductor oxides, and depend on the type of target gas. In an air atmosphere, oxygen adsorption on the oxide surface forms different absorbed oxygen species $\left(\mathrm{O}_{2}^{-}, \mathrm{O}^{-}\right.$or $\left.\mathrm{O}^{2-}\right)$. The different oxygen species depend on the working temperature [27]. The process is described as the following equations:

$$
\begin{gathered}
\mathrm{O}_{2} \text { (gas) } \rightarrow \mathrm{O}_{2} \text { (absorbed) } \\
\left.\mathrm{O}_{2} \text { (absorbed }\right)+\mathrm{e}^{-} \rightarrow \mathrm{O}_{2}{ }^{-} \\
\mathrm{O}_{2}^{-}+\mathrm{e}^{-} \rightarrow 2 \mathrm{O}^{-} \\
\mathrm{O}^{-}+\mathrm{e}^{-} \rightarrow \mathrm{O}^{2-}
\end{gathered}
$$

Apart from the working temperature, different oxygen species are also determined by the grain size. Rumyantseva et al. have investigated the correlations between grain size and oxygen chemisorption for nanocrystalline $\mathrm{SnO}_{2}$ and $\mathrm{In}_{2} \mathrm{O}_{3}$ [28]. The values of coefficient $m$ changes with grain size at $200-400{ }^{\circ} \mathrm{C}$, as shown in Figure 1a,b. The coefficient $m$ value decreases with increasing grain size. When $m=1$, oxygen chemisorption mainly exists in the form of molecular $\left(\mathrm{O}^{2-}\right)$. When $m=0.5$, oxygen species mainly take the form of atomic $\mathrm{O}^{-}$. When $m=0.25$, atomic $\mathrm{O}_{2}{ }^{-}$dominates in the oxygen chemisorption. It can be seen that decrease of $m$ increases the amount of the atomic forms, so grain size enlargement increases the fraction of atomic forms of absorbed oxygen species. Obviously, oxygen chemisorption is affected by the grain size.

The semiconducting oxides can be divided into n-type and p-type depending on the type of majority carrier. Most semiconductor oxide gas sensors are n-type, in which the majority carriers are electrons. For reducing gases in the adsorption process of semiconductor oxides, reductive gases will react with the adsorbed oxygen species and decrease the resistance of the sensor, but when the sensor is exposed to oxidizing gases at a feasible temperature, the gas molecules can take away electrons to form ion gases and react with the chemisorbed oxygen on the surface, leading to changes in the resistance of the sensor. 
(a)

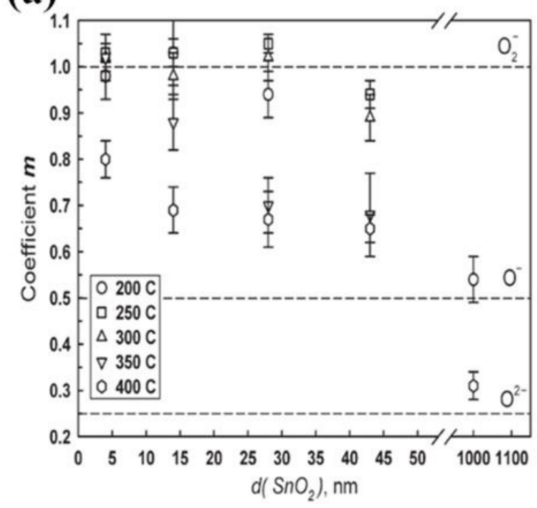

(b)

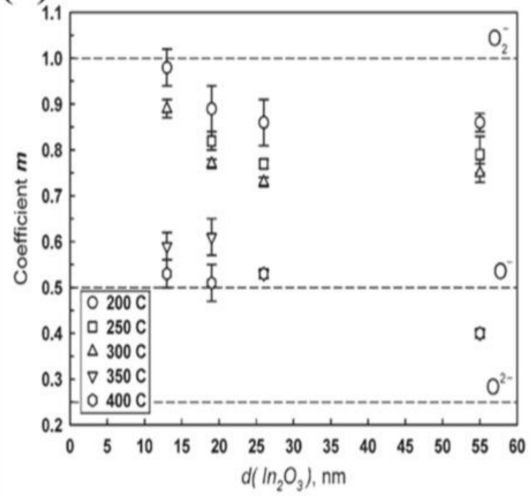

Figure 1. Calculated values of coefficient $m$. (a) $\mathrm{SnO}_{2}$ samples, (b) $\mathrm{In}_{2} \mathrm{O}_{3}$ samples. Reprint from [28] with permission. Copyright (2009) Elsevier.

\subsection{Band Gap}

The electrical properties are affected by the band gap of semiconductor oxides, so the band gap theory is also adopted on the sensing mechanism of gas sensors. Qiao et al. investigated the gas-sensing mechanism of mesoporous $\mathrm{ZnO}$ nanosheets based on the band model [29]. In air, oxygen molecules would absorb on the surface of $\mathrm{ZnO}$ nanosheets to form oxygen ionic species by trapping electrons from the conduction band, synchronously creating an electron depletion zone and upward band bending, as shown in Figure 2a. This variation of band bending also alters the resistance of the sensor. When exposed to an acetylene gas atmosphere, adsorbed oxygen ions would react with the reducing gas and release the trapped electrons back to the conduction band, leading to a reduced thickness of the electron depletion layer and decreasing the resistance of the sensor, as shown in Figure $2 \mathrm{~b}$. Moreover, Qiao et al. proposed that the microstructure affects the acetylene sensing mechanism, that is to say, the synergetic effects of morphology and defect enhanced sensing mechanism of a mesoporous $\mathrm{ZnO}$ nanosheet, as shown in Figure 2c. On the one hand, the adsorption capacity for gas molecules was increased owing to the large specific surface area and gas diffusion was enhanced due to the mesoporous nanostructure. Besides, the thickness of the $\mathrm{ZnO}$ nanosheets was nearly identical to two times the Debye length, resulting in a fully depleted shell layer and an enhanced gas-sensing performance. On the other hand, intrinsic defects in the $\mathrm{ZnO}$ nanosheet act as active sites for oxygen chemisorption and ionization of oxygen species on the surface of $\mathrm{ZnO}$ nanosheet-based sensor, making the sensing reaction go forward in the positive direction, so abundant intrinsic defects lead to more ionized oxygen species. When acetylene gas was injected, more electrons go back to the conduction band, resulting in a lower resistance. Therefore, the enhanced sensing mechanism was attributed to the morphology and defects.
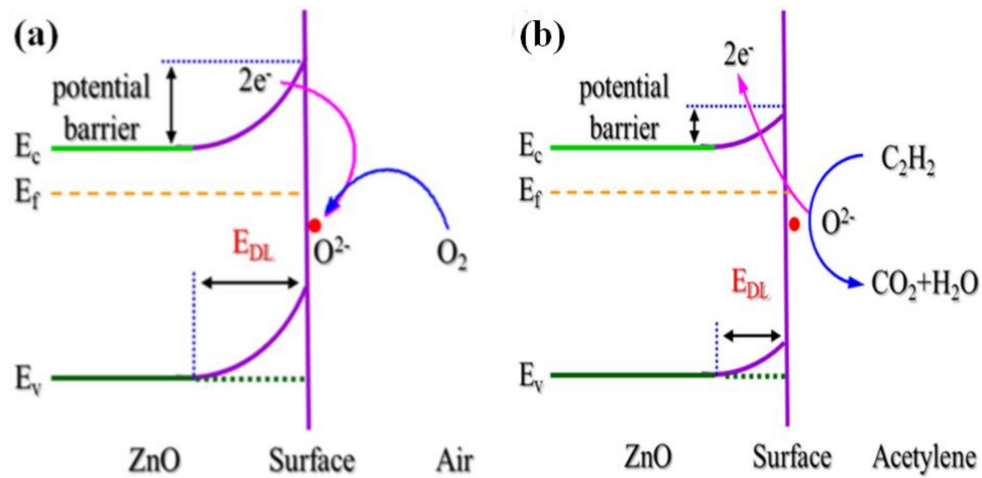

Figure 2. Cont. 


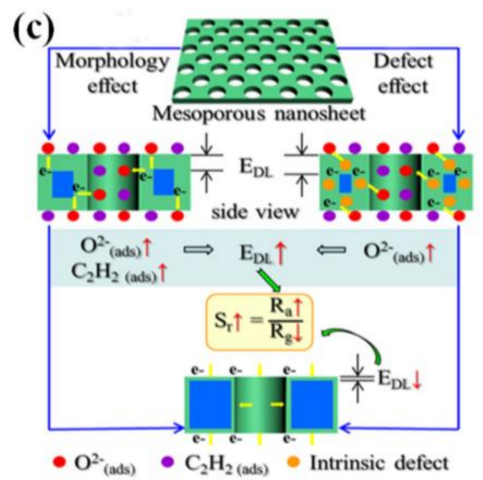

Figure 2. Schematic illustration of acetylene sensing mechanism for $\mathrm{ZnO}$ sensor based on the band model. (a) in air; (b) in acetylene; (c) morphology and defect effects. Reprinted from [29] with permission. Copyright (2017) Elsevier.

\subsection{Schottky Barrier Contact}

Schottky barrier is understood to be a contact between a metal and a semiconductor oxide coming from two different work functions [30]. The combination of noble metal and semiconductor oxide can help improve the gas-sensing performance. Yao et al. investigated the signal enhancement mechanism of $\mathrm{Au} / \mathrm{SnO}_{2}$ hollow multilayered nanosheets [31]. The work function of $\mathrm{Au}$ was larger than that of $\mathrm{SnO}_{2}$, so the electrons are transferred from $\mathrm{SnO}_{2}$ to Au until equilibrium is achieved. In air, a $\mathrm{Au} / \mathrm{SnO}_{2}$ hollow multilayered nanosheet would interact with oxidizing gas, and more electrons are trapped from the $\mathrm{Au} / \mathrm{SnO}_{2}$ hollow multilayered nanosheet surface. In this process, the depletion layer of $\mathrm{Au} / \mathrm{SnO}_{2}$ became wider $(\Delta \mathrm{L})$ and higher $(\Delta \mathrm{H})$ than that of pristine $\mathrm{SnO}_{2}$ due to the $\mathrm{Au} / \mathrm{SnO}_{2}$ junction coming from Schottky barrier contacts, and the resistance of the sensor increases correspondingly, as shown in Figure 3. For the reaction between $\mathrm{Au} / \mathrm{SnO}_{2}$ hollow multilayered nanosheets and $\mathrm{CO}$, the resistance of the sensor becomes lower due to the accumulation of more electrons induced by the nano-Schottky junction between $\mathrm{Au}$ and $\mathrm{SnO}_{2}$.

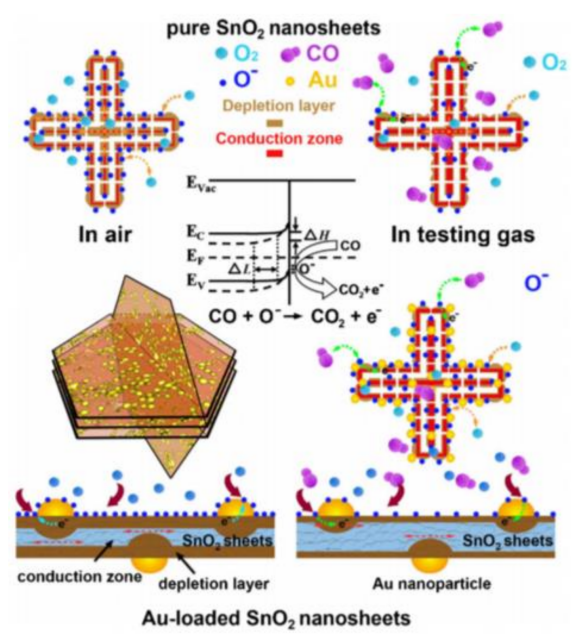

Figure 3. Schematic view of the sensing mechanism and surface processes associated with the reaction with ambient oxygen (left) and testing CO (right). Reprinted from [31] with permission. Copyright (2015) Elsevier.

In addition, the improvement of gas-sensing performance could be attributed to the morphology. The hollow nanostructure and multilayered wall could offer higher surface-to-volume ratios and facilitate gas diffusion, leading to high response and faster response times. Moreover, the unique structure could absorb gases into the inner-surface/outer-surface, resulting in improved gas-sensing performance. 


\subsection{Catalysis-Based Sensing Mechanism}

The semiconductor oxides with an added noble metal can accelerate the reaction process and improve the gas sensor performance. The catalyst can enhance the performance of a sensor in two ways, namely chemical sensitization and electronic sensitization [32]. In the chemical sensitization aspect, the noble metal catalyst facilitates the redox reaction occurring on the surface due to the spillover effect. In this process, more oxygen molecules will absorb on the surface of the semiconductor oxide and drain more free electrons from the semiconductor oxide surface to form adsorbed oxygen species. In the electronic sensitization aspect, the noble metal catalyst acts as an electron acceptor on the surface of the semiconductor oxide, and more electrons will be transferred from the conduction band of the semiconductor oxide, resulting in a greater energy band bending and a broader depletion layer. Thus, the variation of resistance in the catalysis-based semiconductor oxide is larger than that of bare semiconductor oxide, which leads to the increase of the gas-sensing performance.

In addition, the morphology and parameters of the microstructure affect the catalysis sensing process. Zhang et al. indicated that nanorod-assembled porous $\mathrm{SnO}_{2}$ hollow microspheres offered numerous channels for gas diffusion and absorbed more gases on the inner and outer surface [33], so Pd could promote more oxygen dissociation in the chemical sensitization effect. The porous structures accelerate gas diffusion and shorten the response time. Compared to traditional spheres with point-to-point contacts, nanorod-assembled microspheres with multipoint contacts increased the contact area, as shown in Figure 4a. Therefore, there was a wider conductive path for more electrons to transfer in the electronic sensitization effect. The sensing reaction is influenced by the relation between nanorod diameter $\mathrm{D}$ and the Debye length $\mathrm{L}_{\mathrm{d}}$. When the diameter $\mathrm{D}$ is nearly identical to the Debye length $L_{d}$, the free electrons were almost fully depleted resulting in changes of the whole conductivity. The ultrathin nanorod had a small diameter of about $10 \mathrm{~nm}$, and the calculated Debye length was about $6.6 \mathrm{~nm}$, so the ultrathin nanorod meets the condition of $\mathrm{D} \sim 2 \mathrm{~L}_{\mathrm{d}}$, and the amount of ionized oxygen would be maximized, as shown in Figure $4 \mathrm{~b}$.
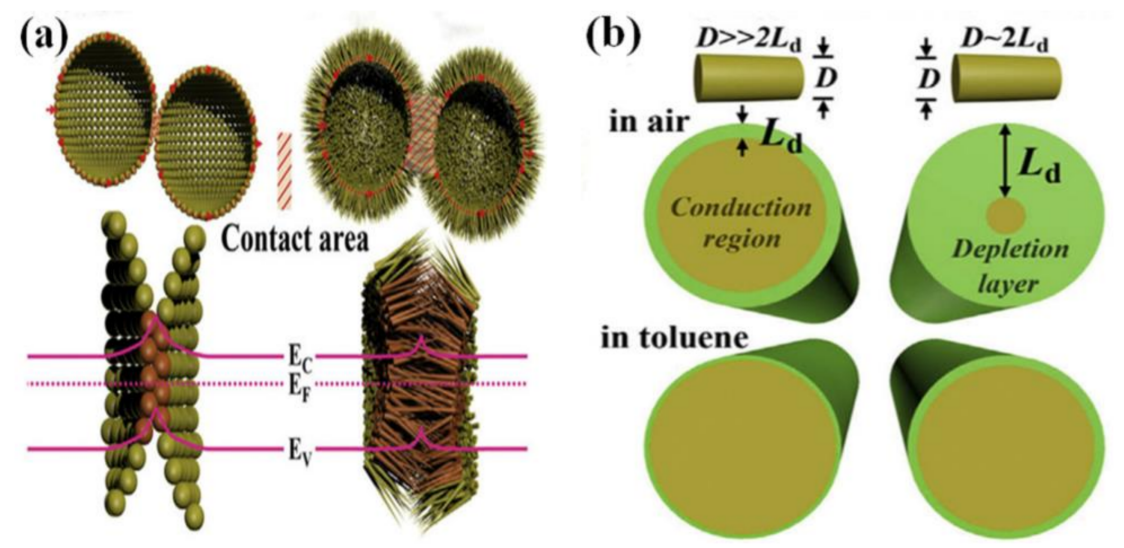

Figure 4. Schematic of catalysis-based sensing mechanism in the nanorod-assembled porous $\mathrm{SnO} 2$ hollow microspheres. (a) interface region associated with the point-to-point (left) and multipoint contacts (right); (b) schematic view of depletion layer on the cross section from nanorods with different diameters. Reprinted from [33] with permission. Copyright (2016) Elsevier.

\subsection{Heterojunction-Based Sensing Mechanism}

Semiconductor oxide heterostructures have been synthesized for the improvement of gas-sensing performances, such as p-p, n-n and p-n junctions. The heterostructure consists of two semiconductor oxides and they have different Fermi energy levels. When they contact with each other, free electrons transfer from the higher Fermi energy level to the lower Fermi energy level. The results indicate that a drain of free electrons occurs above the two semiconductor oxides, creating thicker depletion 
layers and higher resistance at the interface compared with that of a single oxide [34]. As a result, the introduction of a heterojunction has been carried out to improve the gas-sensing performance of sensors. Kim et al. investigated the role of the shell thickness of $\mathrm{CuO} / \mathrm{ZnO}$ core-shell nanowires in the sensing mechanism, as shown in Figure 5. In the case where the shell thickness was nearly identical to $\lambda_{\mathrm{D}}$ of the shell material, a complete electron depletion was generated [35]. When exposed to $C O$ gas, the adsorbed oxygen species would react with $\mathrm{CO}$ gas and release the trapped electrons back into the conduction band to recover its original configuration, leading to an enhanced gas response, as shown in Figure 5a. In another case, the shell thicker than $\lambda_{\mathrm{D}}$ would have only partial electron depletion. When the sensor is exposed to CO gas, CO gas will absorb on the partially depleted shell layer. The resistance of the sensor has a small change, as shown in Figure 5b, so controlling the shell thickness could achieve superior gas-sensing performance.

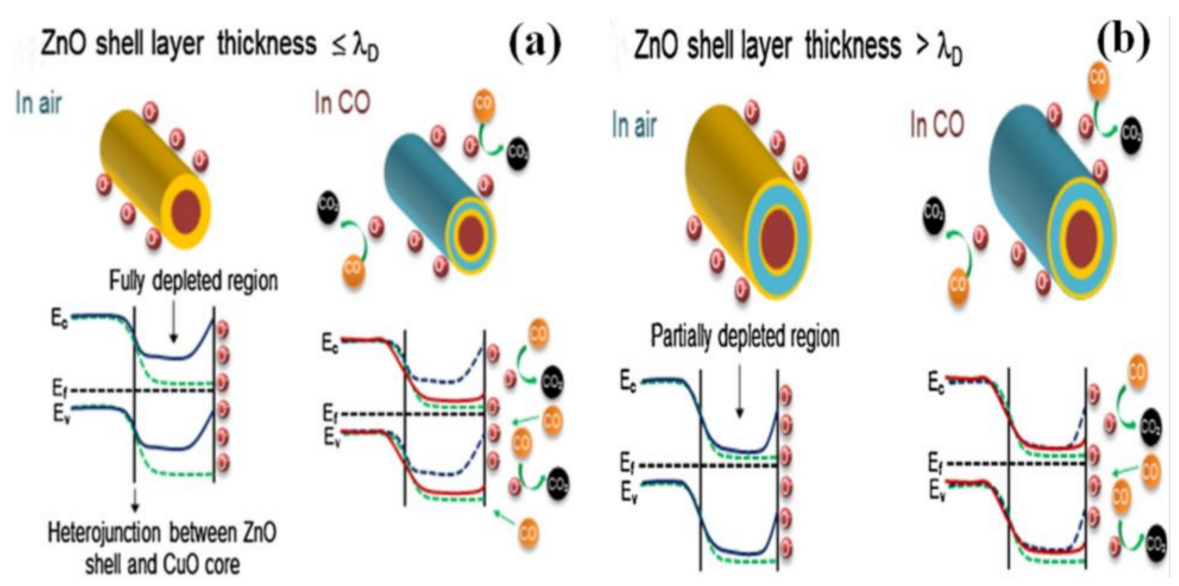

Figure 5. Schematic of heterojunction-based sensing mechanism in the $\mathrm{CuO}-\mathrm{ZnO}$ core-shell nanowires. (a) thinner than ZnO's Debye length; (b) thicker than ZnO's Debye length. Reprinted from [35] with permission. Copyright (2015) Elsevier.

\section{Different Morphologies of Nanomaterials for Gas-Sensing Performances}

Many semiconductor oxides have been widely used in gas sensors, such as $\mathrm{SnO}_{2}$ [36], $\mathrm{ZnO}$ [37], $\mathrm{WO}_{3}$ [38], $\mathrm{In}_{2} \mathrm{O}_{3}$ [39], $\mathrm{NiO}$ [40], $\mathrm{TiO}_{2}$ [41], etc. In recent years, enormous efforts have been made to fabricate various semiconductor oxide morphologies to improve the gas-sensing performances. The morphologies of semiconductor oxides can be classified by dimensionality in some papers [42-44]. On the basis of this classification, semiconductor oxides can be defined as zero-dimensional, one-dimensional, two-dimensional and three-dimensional nanostructured materials. We know that semiconductor oxides with different morphologies have different natures, so we need to get some insight to know the relation between the morphologies and their gas-sensing properties.

\subsection{Zero-Dimensional Sensing Materials}

Zero-dimensional nanoparticles possess a special surface area to adsorb a target gas, which provides an opportunity to improve the gas-sensing performance [45-49]. In addition, the sensitive surface, agglomeration and size of nanoparticle can be adjusted to improve the sensing performance. The gas-sensing reactions occur on the active sites of the surface through gas adsorption, charge transfer and desorption. Consequently, the amount of surface active sites has the possibility to influence the gas response, which is ascribed to improved oxygen adsorption arising from the increment of surface active sites. The increment of surface active sites can be achieved by increasing the specific surface area. This prompts more target gas molecules to participate in the oxidation and reduction reaction. Here we discuss $\mathrm{Cu}_{2} \mathrm{O}$ nanoparticles and their gas-sensing performance. Wang et al. prepared concave $\mathrm{Cu}_{2} \mathrm{O}$ octahedral nanoparticles with $400 \mathrm{~nm}$ in diameter, which displayed better 
gas-sensing performance in the detection of benzene and nitrogen dioxide than $\mathrm{Cu}_{2} \mathrm{O}$ nanorods [50]. As a p-type semiconductor, $\mathrm{Cu}_{2} \mathrm{O}$ nanoparticles react with oxidizing gases $\left(\mathrm{NO}_{2}\right)$, which exhibit a low resistance value, but $\mathrm{Cu}_{2} \mathrm{O}$ nanoparticles interact with a reducing gas $\left(\mathrm{C}_{6} \mathrm{H}_{6}\right)$ representing an opposite trend in resistance. Unlike traditional octahedral structures, $\mathrm{Cu}_{2} \mathrm{O}$ octahedral nanoparticles were akin to icositetrahedron structures with distinctly boundaries, so $\mathrm{Cu}_{2} \mathrm{O}$ nanoparticles with eight sunken faces had a greater specific surface area than the nanorod one. A higher specific surface area provides more active sites for the surface reaction, which was responsible for a higher and faster gas response. Recently, colloidal quantum dots (CQDs) are used in gas sensors due to their large sensitive surface with precise control over nanoparticle size. Based on the advantages of CQDs, the $\mathrm{WO}_{3} \mathrm{CQDs}$-based sensor was exploited to detect $\mathrm{H}_{2} \mathrm{~S}$ gas, for which it possessed a fast response and reduced power consumption at an optimal temperature as low as $80^{\circ} \mathrm{C}$, owing to the extremely small crystal size allowing a stronger surface effect [51].

In general, conglomeration of nanoparticles has been deemed as a factor that has an effect on the sensing performance, restricting the applications of gas sensors. Because there is no guarantee that semiconductor oxides are adequately responsive to target gases in the presence of agglomeration, therefore, the uniform distribution of nanoparticles is important for gas-sensing reactions. Xiao et al. have prepared $\operatorname{In}_{2} \mathrm{O}_{3}$ nanoparticles, having a uniform size with unique diameter $(20-30 \mathrm{~nm})$, as shown in Figure 6a,b . It could be clearly seen that the nanoparticles are dispersed evenly. The gas sensor based on $\operatorname{In}_{2} \mathrm{O}_{3}$ nanoparticles exhibits fast and high response at a rather low operating temperature $\left(60^{\circ} \mathrm{C}\right)$, as shown in Figure $6 c, d$ [52]. This may be attributed to the surface morphology of the nanoparticles. The uniformly dispersed nanoparticles with relatively small size could ensure quick responsiveness. Thus, the $\mathrm{In}_{2} \mathrm{O}_{3}$ nanoparticles as gas sensors have potential for the detection of $\mathrm{NO}_{2}$. In addition, researchers have always endeavored to obtain tiny enough nanoparticles on account of the small size effect. Based on Xu's model [53], the response of the sensor increases remarkably if the particle size (D) of semiconductor oxide is less than or equal to double the width of the space charge layer (L). To investigate the small size effect, Liang et al. have prepared highly monodisperse $\alpha-\mathrm{Fe}_{2} \mathrm{O}_{3}$ nanoparticles about $3 \mathrm{~nm}$ in size by a reverse micro-emulsion method [54]. On the surface of $\alpha-\mathrm{Fe}_{2} \mathrm{O}_{3}$ nanoparticles, oxygen molecules drained electrons from the conduction band and become ionized to $\mathrm{O}_{2}{ }^{-}, \mathrm{O}^{-}$or $\mathrm{O}^{2-}$, which created an electron depleted region called the space charge layer. The width of the space charge layer is about $44 \mathrm{~nm}$. It was evident that the $\alpha-\mathrm{Fe}_{2} \mathrm{O}_{3}$ nanoparticles met the condition of $\mathrm{D} \leq 2 \mathrm{~L}$, so the whole grains were almost fully depleted resulting in changes to the whole conductivity, thus having the capability to enhance the acetone sensing performance, and showing that zero-dimensional nanoparticles exhibit superior sensing abilities for target gases.
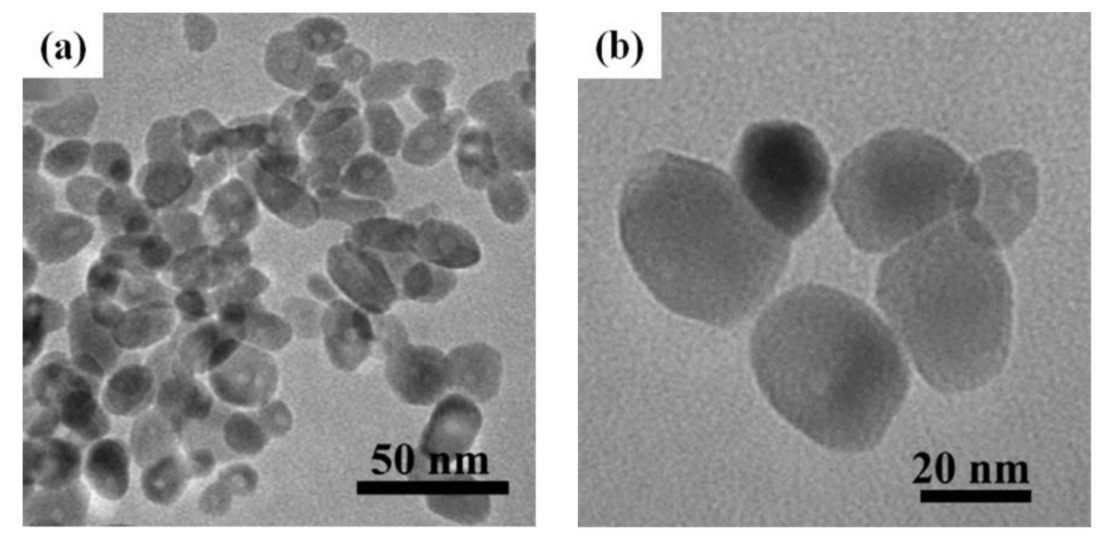

Figure 6. Cont. 

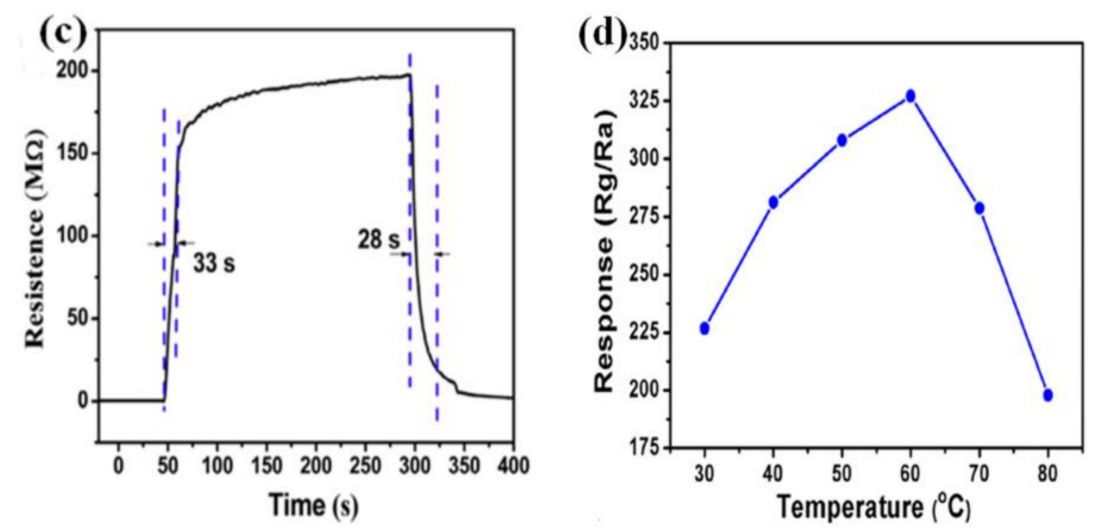

Figure 6. (a,b) TEM images of the $\operatorname{In}_{2} \mathrm{O}_{3}$ nanoparticles; (c) the response and recovery times of $\operatorname{In}_{2} \mathrm{O}_{3}$ nanoparticle sensor towards $20 \mathrm{ppm} \mathrm{NO}_{2}$; (d) Response of the sensor based on $\mathrm{In}_{2} \mathrm{O}_{3}$ nanoparticles to 5 ppm $\mathrm{NO}_{2}$. Reprinted from [52] with permission. Copyright (2016) Elsevier.

\subsection{One-Dimensional Sensing Materials}

One-dimensional nanostructured materials with high aspect (length divided by width) ratio are potential candidates for gas sensors. The lengths of 1D semiconductor oxide particles can be a few millimeters long, but the thickness and widths are only within a limited range between 1 and $100 \mathrm{~nm}$ [55]. More and more people are very enthusiastic about fabricating 1D nanostructures in the forms of nanowires, nanotubes, nanobelts, nanorods, nanofibers, nanobundles, etc. [56-67]. These 1D nanomaterials with enhanced gas-sensing properties are suitable for gas sensors. The gas-sensing performances of 1D nanostructures with various morphologies are summarized in Table 1.

Table 1. Summary of the gas-sensing performances of $1 \mathrm{D}$ nanostructures with various morphologies to different gases.

\begin{tabular}{cccccccccc}
\hline Morphology & Gases & Materials & $\begin{array}{c}\text { Conc. } \\
(\mathbf{p p m})\end{array}$ & $\begin{array}{c}\text { LOD } \\
(\mathbf{p p m})\end{array}$ & $\begin{array}{c}\text { Temp. } \\
\left({ }^{\circ} \mathbf{C}\right)\end{array}$ & $\boldsymbol{\tau}_{\text {res }}$ (s) & $\boldsymbol{\tau}_{\text {rec }}$ (s) & Resp. & Ref. \\
\hline nanowire & $\mathrm{H}_{2}$ & $\mathrm{CuO}$ & 100 & $\mathrm{NA}$ & 300 & 60 & 2 & $340^{\mathrm{b}}$ & {$[68]$} \\
nanowire & $\mathrm{NO}_{2}$ & $\mathrm{SnO}_{2}$ & 2 & $\mathrm{NA}$ & 150 & $25 \mathrm{~min}$ & $45 \mathrm{~min}$ & $6.9^{\mathrm{b}}$ & {$[69]$} \\
nanowire & $\mathrm{H}_{2} \mathrm{~S}$ & $\mathrm{SnO}_{2}$ & 10 & $\mathrm{NA}$ & 250 & 2.3 & $5 \mathrm{~min}$ & $380^{\mathrm{a}}$ & {$[70]$} \\
nanorod array & $\mathrm{O}_{2}$ & $\mathrm{TiO}_{2}$ & $4 \%$ & $\mathrm{NA}$ & $\mathrm{RT}$ & 40 & 75 & $1.68^{\mathrm{b}}$ & {$[71]$} \\
nanorod & $\mathrm{NO}_{2}$ & $\mathrm{SnO}_{2}$ & 5 & 0.03 & 150 & $5.9 \mathrm{~min}$ & $2.6 \mathrm{~min}$ & $5310^{\mathrm{b}}$ & {$[72]$} \\
nanorod & $\mathrm{CH}_{4}$ & $\mathrm{TiO}_{2}$ & 60 & $\mathrm{NA}$ & $\mathrm{RT}$ & 45 & 33 & $6028^{\mathrm{a}}$ & {$[73]$} \\
nanofiber & ethanol & $\mathrm{WO}_{3}$ & 100 & $\mathrm{NA}$ & 350 & $\mathrm{NA}$ & $\mathrm{NA}$ & $62^{\mathrm{a}}$ & {$[74]$} \\
nanotube & methanol & $\mathrm{ZnO}$ & 700 & $\mathrm{NA}$ & $\mathrm{NA}$ & $2.24 \mathrm{~min}$ & 1.03 min & $51.23 \%^{\mathrm{c}}$ & {$[75]$} \\
nanobelt & $\mathrm{NO}$ & $\mathrm{ZnO}$ & 50 & 0.5 & $\mathrm{RT}$ & $\mathrm{NA}$ & $\mathrm{NA}$ & $6.5^{\mathrm{b}}$ & {$[76]$} \\
\hline \multicolumn{7}{c}{}
\end{tabular}

Nanowires possess a high aspect ratio, thus increasing the surface-to-volume ratio, leading to wonderful stabilities and superior gas-sensing properties. For instance, $\mathrm{WO}_{3}$ nanowires have been used for NO gas sensors, which showed high response (37) with fast response and recovery time (68 s/88 s) [77]. The enhanced gas-sensing performance was related to the large surface-to-volume ratio of the very fine nanowires. Compared with the increased surface-to-volume ratio, the improvement of gas-sensing performance caused by the size effect of semiconductor oxide is more significant [78]. This is due to the fact that the surface of a semiconductor oxide becomes more active as the size shrinks. In order to explore the dependence of the he gas-sensing performance on the nanowire diameter, Lupan et al. have prepared $\mathrm{ZnO}$ nanowires with different diameters $(100-300 \mathrm{~nm}$ ) for the detection of hydrogen [79]. The results indicated that $\mathrm{ZnO}$ nanowires with $100 \mathrm{~nm}$ in diameter showed the best response value to $100 \mathrm{ppm}_{2}$ at room temperature. The $\mathrm{ZnO}$ nanowires with smaller diameter meant that more atoms participated in the surface gas-sensing reactions, pointing out the importance of the size effect. 
Recently, arrays of 1D nanowires were found to benefit gas diffusion on account of their loose structural features. Qin et al. have prepared gas sensors based on aligned arrays of $\mathrm{W}_{18} \mathrm{O}_{49}$ nanowires [80]. Due to their beneficial sensing structure, the $\mathrm{W}_{18} \mathrm{O}_{49}$ nanowire arrays possessed wonderful $\mathrm{NO}_{2}$ sensing performance with high selectivity and fast response/recovery characteristics. The aligned nanowires arrays exhibited good interface performance with good adhesion and electrical contact, making a sensor with perfect stability. Besides, the intercrossing nanowire/nanowire junctions provided electrical paths for increasing the potential barrier height, contributing to outstanding changes in the resistance.

Nanotubes not only have good porosity but also a large surface area due to their hollow structures. Recently, nanotubes have been prepared by many methods, including template sol-gel processes, electrospinning, atomic layer deposition, and hydrothermal synthesis, etc. For instance, $\operatorname{In}_{2} \mathrm{O}_{3}$ nanotubes were fabricated by coaxial electrospinning in order to enhance their $\mathrm{HCHO}$ sensing properties. The nanotubes were composed of numerous $\operatorname{In}_{2} \mathrm{O}_{3}$ grains, which showed a rough surface [81]. It was found that the gas-sensing performance can be improved by adjusting the grain size. Moreover, the grain sizes of $\operatorname{In}_{2} \mathrm{O}_{3}$ nanotubes could be tuned by changing the calcination temperature. As the gas-sensing properties of $\mathrm{HCHO}$ gas were investigated, the gas sensor exhibited the highest response for $\mathrm{In}_{2} \mathrm{O}_{3}$ nanotubes calcined at $400{ }^{\circ} \mathrm{C}$ compared to $\operatorname{In}_{2} \mathrm{O}_{3}$ nanotubes calcined at $600{ }^{\circ} \mathrm{C}$ and $800^{\circ} \mathrm{C}$. The results indicated that gas-sensing performance increased with decreasing grain sizes at relatively low calcination temperature.

Generally, ultra-long 1D nanostructured materials afford an opportunity for electron transport along the axial direction, contributing to enhanced gas-sensing characteristics of the semiconductor oxides. Apart from the special nanostructure, exposed specific crystal facets of semiconductor oxides can also lead to an improved gas-sensing properties [82]. For example, Yang et al. synthesized ultra-long single crystalline $\mathrm{MoO}_{3}$ nanobelts of about $200 \mu \mathrm{m}$ in length and $200-400 \mathrm{~nm}$ in width, as shown in Figure 7a. The response increased with increasing operating temperature until the response reached a maximum value of 582 toward $50 \mathrm{ppm}$ TMA at $240{ }^{\circ} \mathrm{C}$ (Figure $7 \mathrm{~b}$ ). The high response was ascribed to a direct path to electronic transmission along the axial direction provided by ultra-long $\mathrm{MoO}_{3}$ nanobelts, resulting in a rapid electron transfer [83]. In addition, due to the fact the (010) surface of $\mathrm{MoO}_{3}$ was exposed, it would be easier to form oxygen vacancies thus enhancing the activities for the improvement of the gas-sensing properties.
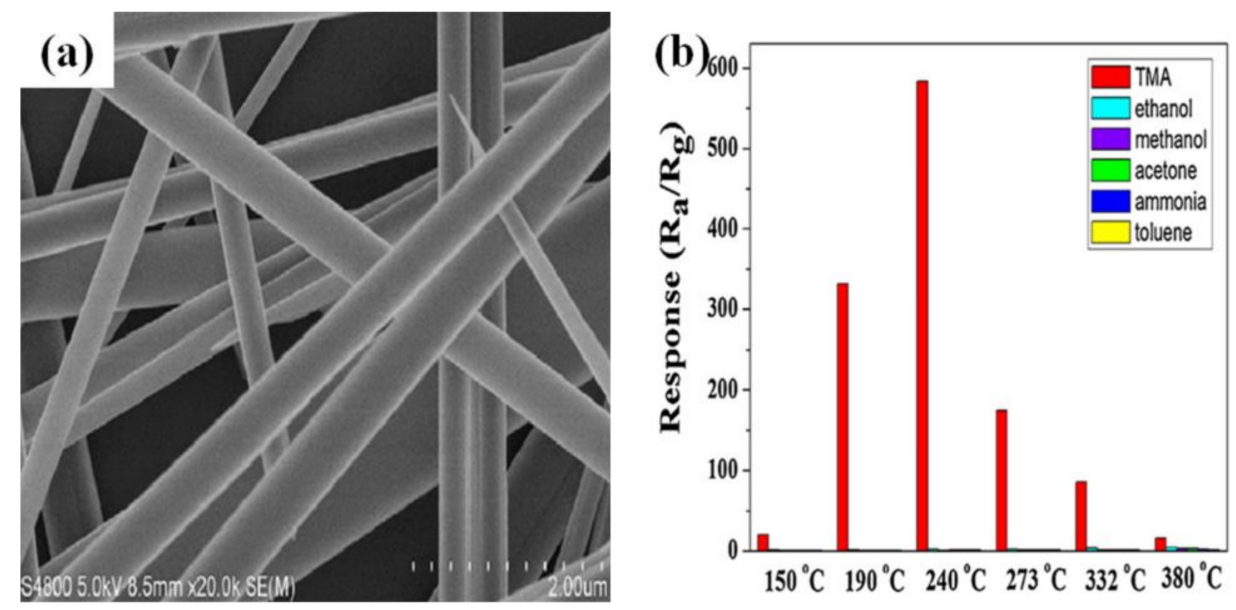

Figure 7. (a) High resolution FESEM image of ultra-long $\mathrm{MoO}_{3}$ nanobelts; (b) Response of the sensor based on ultra-long $\mathrm{MoO}_{3}$ nanobelts exposure of different gas at different temperatures. Reprint from [83] with permission. Copyright (2015) Elsevier.

Among various 1D nanostructured materials for gas-sensing applications, researchers have been especially interested in nanofibers. Nanofibers can offer high specific surface area due to both a long length and small diameter. Optimizing the morphology of nanofibers is of importance for improving 
the performance of gas sensors. Khalil et al. have investigated how controlling the morphology could be an effective means to achieve the best gas-sensing performance of $\mathrm{NiO}$ nanofibers [84]. The morphologies of $\mathrm{NiO}$ nanofibers varied from rough and discontinuous to smooth and continuous with increasing NiAc/PVA ratios. As mentioned earlier, the sensor response increased with increasing surface area. At the same time, the gas-sensing performances of sensors are also affected by the inter-particle connectivity. Yoon et al. discussed the importance of inter-particle connectivity and showed that the response of nanofibers decrease with decreasing inter-particle connectivity [85]. Thus, $\mathrm{NiO}$ nanofibers obtained from $1.5 \mathrm{wt} / \mathrm{wt}$ precursors possessed the highest response to $\mathrm{H}_{2}$ and $\mathrm{NH}_{3}$, which was ascribed to a combination of high surface area and good inter-particle connectivity. The result suggested that the high surface area was as important as the inter-particle connectivity.

\subsection{Two-Dimensional Sensing Materials}

In recent years, 2D nanostructures have received strong research interest because of their unique morphologies. Thus, they can be used in many fields, such as gas sensors [86], lithium-ion batteries [87], supercapacitors [88], photoelectrochemistry [89], and photocatalysts [90]. Recently there have been a certain number of publications about 2D semiconductor oxides in gas sensors [91-94]. For example, small crystallite $\mathrm{MoO}_{3}$ nanoplates prepared by ultrasonic spray pyrolysis exhibited gas-accessible nanostructures with a relatively low detection limit (45 ppb TMA) [95]. The $\mathrm{MoO}_{3}$ nanoplate-based sensor showed ultrasensitivity and ultraselectivity to TMA. The ultrasensitivity to TMA was related to the thin nanosheets with large surface-to-volume ratio, inducing greater electron depletion and faster gas diffusion toward the entire surface of the $\mathrm{MoO}_{3}$ nanoplates. In addition, $\mathrm{MoO}_{3}$ as an acidic oxide had a high preference to react with basic gases, leading to ultraselectivity to TMA. In other words, the nature of TMA could lead to stronger chemisorption on the surface of $\mathrm{MoO}_{3}$, thereby increasing the electron transfer and improving the gas response.

Porous nanostructures will not only help gas interaction occurring on the surface but also facilitate the penetration of gas into the sensing material, relative to a dense structure. Porous nanostructures can be classified according to the pore size [96]. The size of micropore is smaller than $2 \mathrm{~nm}$ whereas macroporous nanostructures have pore widths larger than $50 \mathrm{~nm}$. Mesoporous materials have pore diameters of $2-50 \mathrm{~nm}$. In order to better improve the gas-sensing performance, mesoporous nanostructures and 2D nanosheets could be combined to exert their respective advantages. For example, Wang et al. have synthesized mesoporous $\operatorname{In}_{2} \mathrm{O}_{3}$ ultrathin nanosheets that presented superior response (213) as well as short response times $(4 \mathrm{~s})$ to $\mathrm{NO}_{\mathrm{x}}$ at a relatively low operating temperature with a detection limit as low as $10 \mathrm{ppb}$ [97]. The nanosheets with ultrathin thickness of $3.7 \mathrm{~nm}$ possessed a number of active sites, which lead to an increased response to $\mathrm{NO}_{\mathrm{x}}$. Moreover, the mesoporous structures shorten the transport path and enhance gas diffusion. Thus, the advantaged combination achieves the improvement of the gas-sensing performance.

In addition, network-like structures can contribute to rapid gas adsorption on the entire surface of a semiconductor oxide, leading to significantly increased gas-sensing performance. Networked nanosheet arrays of $\mathrm{Co}_{3} \mathrm{O}_{4}$ were prepared for the detection of $\mathrm{NH}_{3}$ [98]. The morphologies of $\mathrm{Co}_{3} \mathrm{O}_{4}$ crossed nanosheets arrays are shown in Figure 8a,b. The inset of Figure 3a showed the corresponding $\mathrm{Co}_{3} \mathrm{O}_{4}$ crossed nanosheets grown directly on substrates. The crossed nanosheets with cavities offered rapid electrical channels, ensuring that the network-like structure presented good gas-sensing performance. Besides, it could be seen that the $\mathrm{Co}_{3} \mathrm{O}_{4}$ nanosheet was composed of many small grains, as shown in Figure 8c. This indicated that the nanosheet surface structure facilitated gas diffusion. Figure $8 \mathrm{~d}$ shows the response/recovery curves for different concentrations of $\mathrm{NH}_{3}$ gas. As can be seen, the $\mathrm{Co}_{3} \mathrm{O}_{4}$ nanosheet arrays possessed good responses even at a relatively low concentration of $0.2 \mathrm{ppm} \mathrm{NH}_{3}$ due to the fact the nanosheet intersect with each other with a superior open structure. The special structure not only prevents aggregation but also supplies a larger effective surface to react with target gases, leading to an enhanced gas response. 

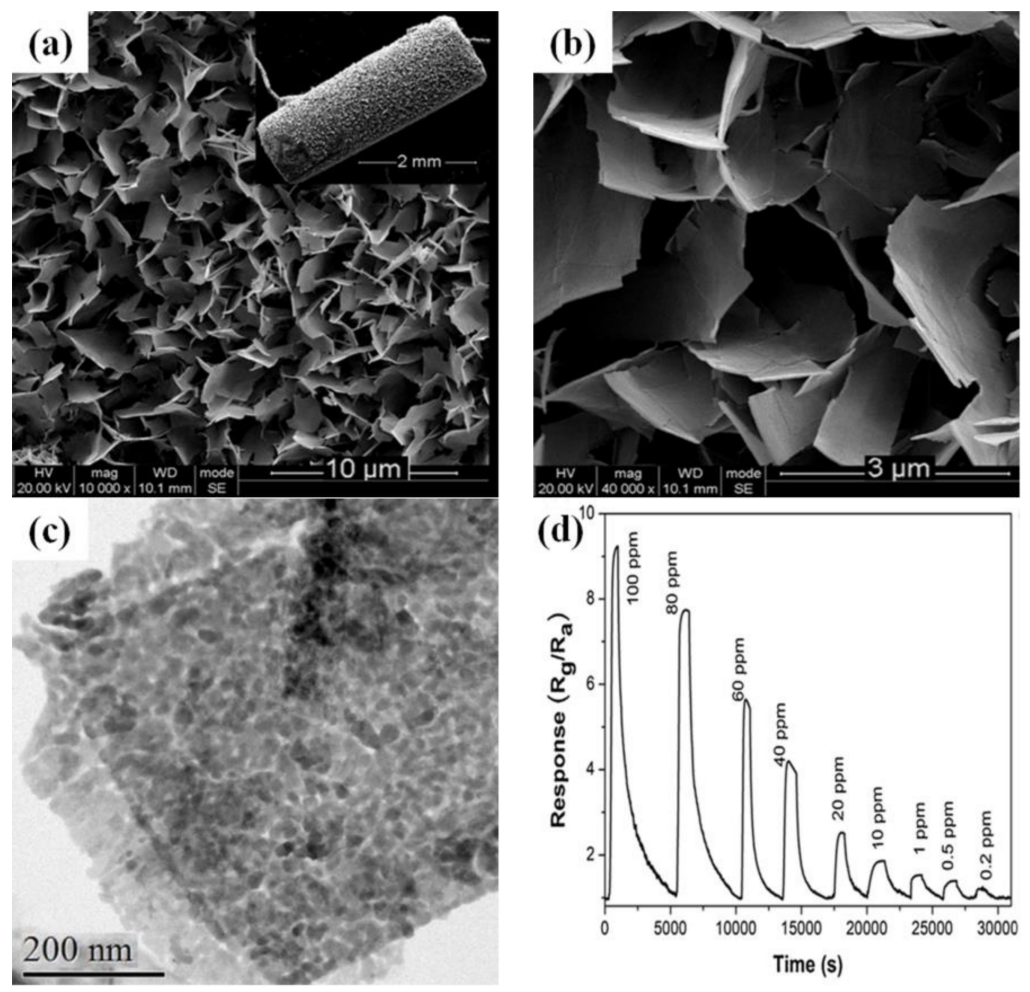

Figure 8. (a) SEM image of samples with magnification of 10,000 times (inset indicates the panoramic image of the $\mathrm{Co}_{3} \mathrm{O}_{4}$ on the surface of alumina tube); (b) SEM images with magnification of 40,000 times; (c) TEM image of $\mathrm{Co}_{3} \mathrm{O}_{4}$ nanosheet; (d) Dynamic response-recovery curve of the sensor based on $\mathrm{Co}_{3} \mathrm{O}_{4}$ nanosheet arrays to $\mathrm{NH}_{3}$ gas at the room temperature. Reprinted from [98] with permission. Copyright (2016) Elsevier.

Semiconductor oxide-based thin films are also a kind of 2D sensing material, and the surface roughness of the films can enhance the sensing properties of gas sensors. Escalante et al. prepared $\mathrm{ZnO}$ films which displayed good gas-sensing properties toward $200 \mathrm{ppm} \mathrm{CO}$ at an operating temperature of $300{ }^{\circ} \mathrm{C}$ by single source chemical vapor deposition [99]. The plate-like structure on the surface of $\mathrm{ZnO}$ film displayed morphology of surface roughness, determining the effective surface area of the film and resulting in a significant impact on the gas response. In addition, the $\mathrm{ZnO}$ film contained plate-like structures with polycrystalline formation and thus gas molecules can be stored in the boundary and interface of grains, leading to an enhanced gas-sensing performance. Aside from these examples, the gas-sensing performances of 2D nanostructures with various morphologies were reported in many references (Table 2) and will be summarized in this review.

Table 2. Summary of the gas-sensing performances of 2D nanostructures with various morphologies to different gases.

\begin{tabular}{|c|c|c|c|c|c|c|c|c|c|}
\hline Morphology & Gases & Materials & Conc. (ppm) & LOD (ppm) & Temp. $\left({ }^{\circ} \mathrm{C}\right)$ & $\tau_{\text {res }}(\mathrm{s})$ & $\tau_{\text {rec }}(\mathrm{s})$ & Resp. & Ref. \\
\hline nanosheet & acetone & $\mathrm{Co}_{3} \mathrm{O}_{4}$ & 100 & 1.8 & 150 & NA & NA & $11.4^{\mathrm{b}}$ & [100] \\
\hline nanosheet arrays & $\mathrm{NO}_{2}$ & $\mathrm{ZnO}$ & 10 & NA & 180 & 3 & 12 & $20^{b}$ & [101] \\
\hline nanoplate & $\mathrm{H}_{2} \mathrm{~S}$ & $\mathrm{TiO}_{2}$ & 100 & NA & 300 & NA & NA & $5.5^{\mathrm{a}}$ & [102] \\
\hline Nanoplate arrays & xylene & $\alpha-\mathrm{MoO}_{3}$ & 100 & NA & 370 & 1 & 15 & $19.2^{\mathrm{a}}$ & [104] \\
\hline thin film & $\mathrm{NO}_{2}$ & $\mathrm{WO}_{3}$ & 1 & NA & 300 & 7 & 8 & $4.1^{\mathrm{b}}$ & [105] \\
\hline thin film & acetone & $\mathrm{ZnO}$ & 100 & NA & 280 & 6 & 18 & $30^{\mathrm{a}}$ & [106] \\
\hline nanowall & $\mathrm{NO}_{2}$ & $\mathrm{ZnO}$ & 50 & NA & 450 & 23 & 11 & $6.4^{\mathrm{b}}$ & [108] \\
\hline
\end{tabular}

${ }^{\mathrm{a}} \mathrm{S}=\mathrm{R}_{\mathrm{a}} / \mathrm{R}_{\mathrm{g}} ;{ }^{\mathrm{b}} \mathrm{S}=\mathrm{R}_{\mathrm{g}} / \mathrm{R}_{\mathrm{a}} ; \mathrm{LOD}$ : limit of detection; NA = not available. 


\subsection{Three-Dimensional Sensing Materials}

Three-dimensional hierarchical nanostructures are assembled from low dimensional nanomaterials, including 0D nanoparticles, 1D nanorods and 2D nanosheets. Three-dimensional hierarchical nanostructures are considered to be a more potential sensing material for detecting toxic gases than $0 \mathrm{D}, 1 \mathrm{D}, 2 \mathrm{D}$ nanostructures, because they can provide a large surface area, abundant active sites and fast interfacial transport. Hence, many semiconductor oxides with three-dimensional hierarchical nanostructures have been prepared to detect gases.

The conglomeration of OD nanoparticles has been deemed as an obstacle in the improvement of gas-sensing performance, so researchers put forward an idea that $\mathrm{OD}$ nanoparticles as building blocks be assembled into three-dimensional hierarchical nanostructures, thus improving the gas-sensing performance. For instance, Wu et al. synthesized a three-dimensional hierarchical $\mathrm{Co}_{3} \mathrm{O}_{4}$ nanostructure that was composed of OD nanoparticles with an average size of $20 \mathrm{~nm}$ [109]. The unique 3D structure exhibited superior response to $100 \mathrm{ppm} \mathrm{NH}_{3}$ gas, rapid response time of $2 \mathrm{~s}$ and a detection limit as low as $0.5 \mathrm{ppm}$ at room temperature. This was because of the fact that the hierarchical architecture provided more channels for electron transmission and facilitated gas diffusion toward the $\mathrm{Co}_{3} \mathrm{O}_{4}$ surface as well as the bulk. The connectivity between the particles in the $3 \mathrm{D}$ hierarchical $\mathrm{Co}_{3} \mathrm{O}_{4}$ materials offered higher density of defects, which ensured the fast adsorption into deeper regions of the sensing materials.

Generally, 1D nanorods are an important assembly element that can facilitate fast electron transfer and increase more the sensing activity sites due to their high aspect ratio. Very recently, a $3 \mathrm{D} \mathrm{SnO}_{2}$ hierarchical nanostructure with nanorod assembled elements showed remarkably improved response compared to a commercial $\mathrm{SnO}_{2}$ nanopowder, which was ascribed to a dramatic enhancement of surface accessibility and gas diffusion resulting from the unique loose and porous 3D structure [110]. Further, Li et al. have prepared loose-, moderate- and close-assembled $\mathrm{SnO}_{2}$ nanorod-assembled urchins by tuning their assembly densities [111]. The results indicated that the close-assembled urchins take more time in gas diffusion due to their small pores and long diffusion lengths. Besides, the poor contact among nanorods in the loose-assembled urchins hinders efficient charge transfer. A comparative study indicated that moderate-assembled urchins exhibited the best gas-sensing performance toward ethanol, meaning that there might be an optimized assembly density range which offers enough space for gas diffusion as well as a sufficient contact network for charge transfer.

Two-dimensional nanosheets are also used as building blocks in hierarchical nanostructures, because they have large specific surface areas. The flower-like $\mathrm{Co}_{3} \mathrm{O}_{4}$ structures were composed of single-crystalline nanosheets, and each nanosheet contained numerous pores with an ultrahigh density [112]. The unique structure showed not only superior response and short response/recovery time, but also excellent stability toward xylene compared with commercial $\mathrm{Co}_{3} \mathrm{O}_{4}$. This may be attributed to single-crystalline nanosheets with good stability as well as a porous structure with a high permeability. Moreover, the flower-like structures provided much more contacts between gas molecules and semiconductor oxides and the enlarged specific surface area offered not only efficient diffusion paths, but also more active sites for gas absorption/desorption.

In order to gain a better understanding of the morphology-dependent gas-sensing performance of three-dimensional hierarchical nanostructures, Diao et al. have prepared three different hierarchical $\mathrm{ZnO}$ microstructures (sphere-like, cauliflower-like and sisal-like) to detect $\mathrm{H}_{2} \mathrm{~S}$, as shown in Figure $9 \mathrm{a}-\mathrm{c}$ [113]. The response of a $\mathrm{ZnO}$ nanowire-assembled spherical structure was much higher than that of the cauliflower-like structure and sisal-like structure, respectively, for $1000 \mathrm{ppb}$ of $\mathrm{H}_{2} \mathrm{~S}$ as shown in Figure 9d. The higher response of sphere-like microstructures might be ascribed to the nature of the particle-to-particle contacts. Herein, particle-to-particle contacts result from nanowire-to-nanowire contacts, however, the effective particle-to-particle contacts had an obvious decrease owing to the low dimension nanowires, but the sphere-like microstructures were covered by very large amounts of nanowires, thus enhancing particle-to-particle contacts and motivating the changes of sensor resistance. Consequently, sphere-like microstructures presented the best sensing performance. 
(a)
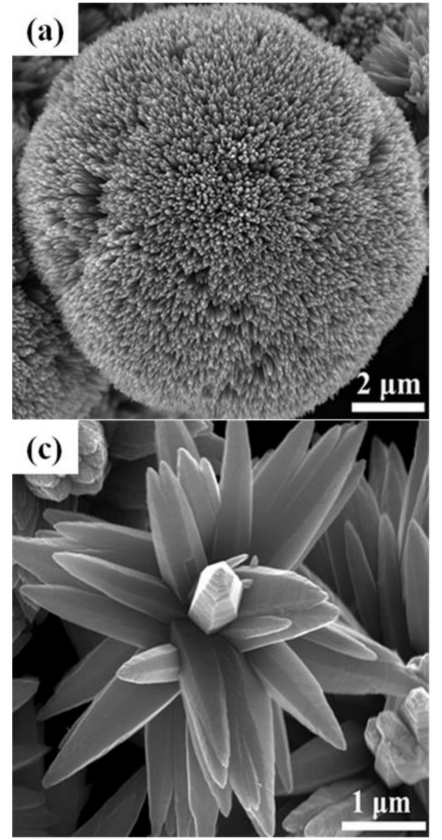
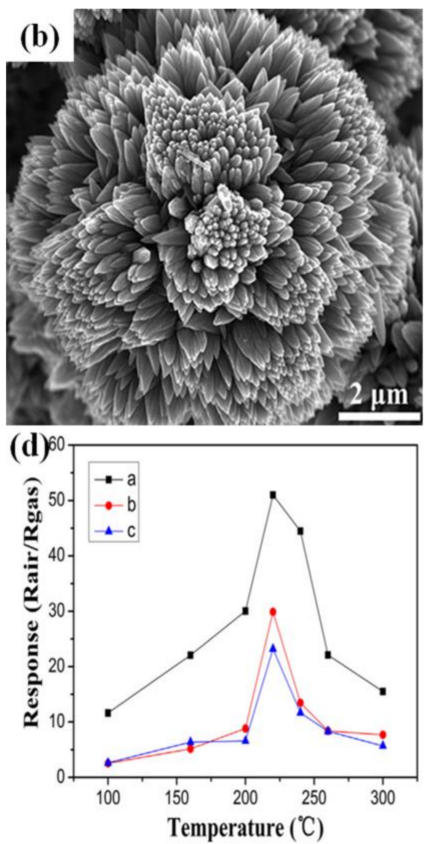

Figure 9. (a) FESEM image of sphere-like ZnO microstructure; (b) FESEM image of cauliflower-like $\mathrm{ZnO}$ microstructure; (c) FESEM image of sisal-like $\mathrm{ZnO}$ microstructure; (d) The response of different hierarchical $\mathrm{ZnO}$ microstructures sensors to $1000 \mathrm{ppb} \mathrm{H}_{2} \mathrm{~S}$ at different operating temperature $\left(100-300{ }^{\circ} \mathrm{C}\right)$. Reprinted from [113] with permission. Copyright (2015) Elsevier.

More recently, 3D macro-mesoporous structure was thought to be potential candidates for gas sensor applications due to their high porosity and less agglomerated configuration. The structure facilitates gas permeation and shortens gas diffusion length, thus contributing to a greatly improved gas-sensing performance. Liu et al. synthesized 3D interconnected macro-mesoporous $\mathrm{ZnO}$ nanostructures with different macropore sizes [114]. It was found that 3D $\mathrm{ZnO}$ nanostructures with interconnected channels between two mesoporous exhibited excellent sensing performances toward acetone, whereas $\mathrm{ZnO}$ nanoparticles showed a lower response due to a tortuous and long pathway. In addition, the largest macropore in the 3D ZnO nanostructures provided the largest cavities and wonderful channels for gas molecules, leading to the best response to $100 \mathrm{ppm}$ acetone with a value of about 137 . In order to prove the selectivity of $3 \mathrm{D} \mathrm{ZnO}$ nanostructures, the sensing material was reacted with acetone and methanol, respectively.

Table 3. Summary of the gas-sensing performances of 3D nanostructures with various morphologies to different gases.

\begin{tabular}{|c|c|c|c|c|c|c|c|c|c|}
\hline Morphology & Gases & Materials & Conc. (ppm) & LOD (ppm) & Temp. $\left({ }^{\circ} \mathrm{C}\right)$ & $\tau_{\text {res }}(\mathrm{s})$ & $\tau_{\text {rec }}(\mathrm{s})$ & Resp. & Ref. \\
\hline microsphere & $\mathrm{NO}_{2}$ & $\mathrm{In}_{2} \mathrm{O}_{3}$ & 1 & NA & 145 & 60 & 30 & $132^{b}$ & {$[115]$} \\
\hline microsphere & $\mathrm{HCHO}$ & $\mathrm{SnO}_{2}$ & 100 & NA & 200 & 17 & 25 & $38.3^{a}$ & [116] \\
\hline flower-like & TEA & $\alpha-\mathrm{MoO}_{3}$ & 100 & 0.5 & 250 & 3 & 1283 & $416^{\mathrm{a}}$ & [117] \\
\hline flower-like & ethanol & $\mathrm{NiO}$ & 400 & NA & 300 & 4 & 8 & $32^{b}$ & [119] \\
\hline flower-like & ethanol & $\mathrm{ZnO}$ & 100 & 0.2 & 260 & NA & NA & $123^{a}$ & [120] \\
\hline flower-like & acetic acid & $\mathrm{SnO}_{2}$ & 100 & NA & 260 & 18 & 11 & $47.7^{\mathrm{a}}$ & [121] \\
\hline leaf-like & acetone & $\alpha-\mathrm{Fe}_{2} \mathrm{O}_{3}$ & 200 & NA & 260 & 8 & 9 & $95.4^{\mathrm{a}}$ & [124] \\
\hline urchin-like & ethanol & $\mathrm{WO}_{3}$ & 100 & NA & 350 & 28 & 12 & $68.56^{\mathrm{a}}$ & [125] \\
\hline cactus-like & acetone & $\mathrm{NiO}$ & 100 & NA & 260 & 24 & 39 & $13.51^{b}$ & [126] \\
\hline spindle-like polyhedra & $\mathrm{HCHO}$ & $\mathrm{In}_{2} \mathrm{O}_{3}$ & 20 & NA & 240 & 1 & 2 & $8.2^{\mathrm{a}}$ & [127] \\
\hline
\end{tabular}

${ }^{\mathrm{a}} \mathrm{S}=\mathrm{R}_{\mathrm{a}} / \mathrm{R}_{\mathrm{g}} ;{ }^{\mathrm{b}} \mathrm{S}=\mathrm{R}_{\mathrm{g}} / \mathrm{R}_{\mathrm{a}} ; \mathrm{LOD}$ : limit of detection; $\mathrm{NA}=$ not available. 
The results revealed a prominent selectivity to acetone compared with methanol, owing to a higher electron density and more released electrons. To date, there are many articles published on the topic of fabricating 3D nanostructures with various morphologies. The gas-sensing performances of 3D nanostructures with various morphologies are summarized in Table 3.

\section{Hollow Semiconductor Oxide Structures for Gas-Sensing Performance}

A hollow structure may facilitate gas diffusion of a semiconductor oxide, which can effectively improve the performance of sensors. Compared with solid nanostructures, nanostructures with hollow interiors achieve better characteristics by introducing the inner-surface into the reactions. Therefore, hollow semiconductor oxide structures which can absorb gases into the inner-surface/outer-surface are widely used in the gas sensor field [128-132]. Figure 10a-f presented different morphologies and structural characteristics of some hollow nanostructures [133-138].
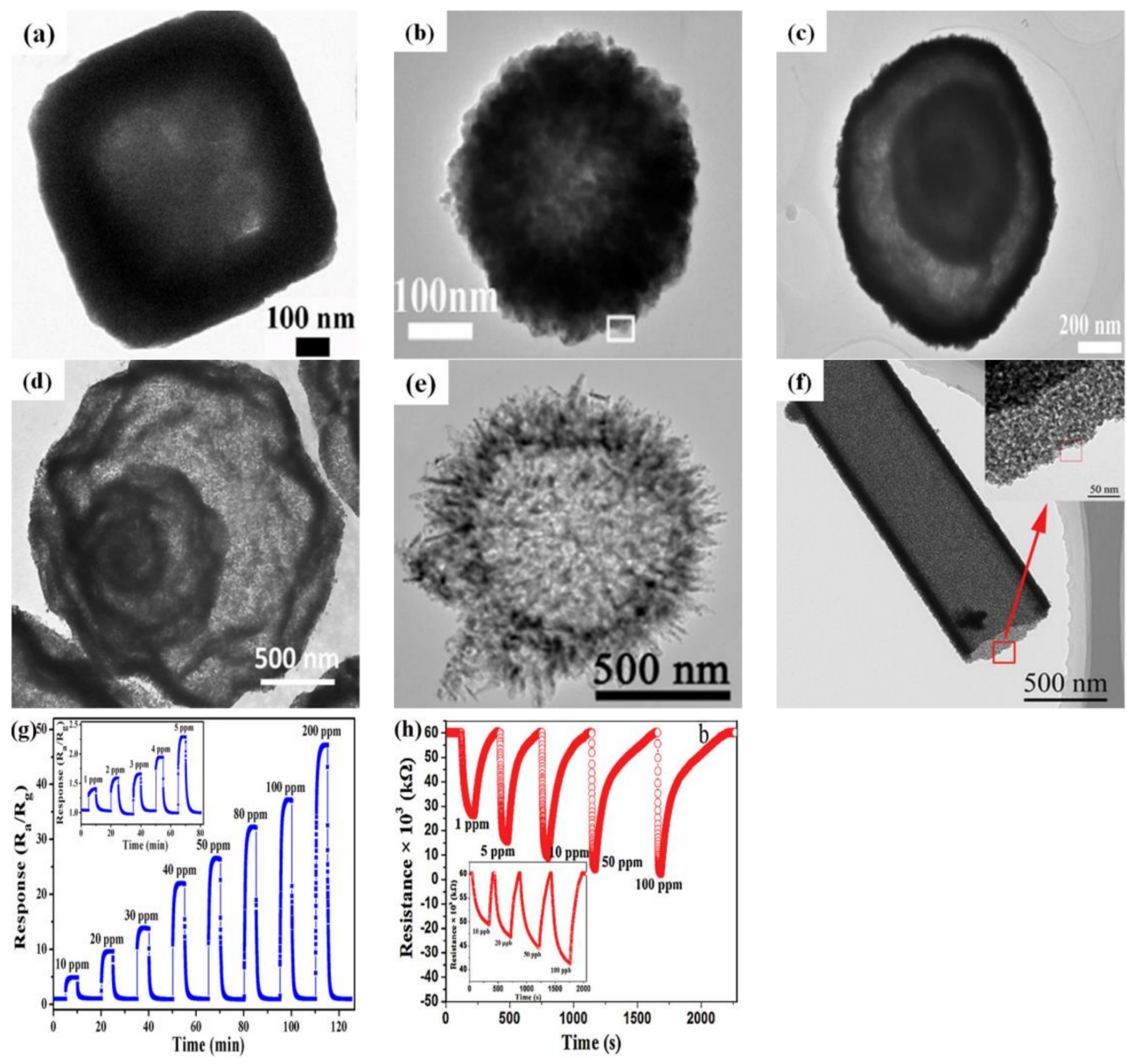

Figure 10. (a) TEM image of $\mathrm{ZnSnO}_{3}$ hollow cube; (b) TEM image of $\mathrm{SnO}_{2}$ hollow spheres; (c) TEM image of multi-shelled $\mathrm{ZnO}$ hollow sphere; (d) TEM image of multi-shelled $\mathrm{Cr}_{2} \mathrm{O}_{3}$ hollow sphere; (e) TEM image of $\mathrm{ZnFe}_{2} \mathrm{O}_{4}$ hollow microsphere; (f) TEM image of $\mathrm{SnO}_{2}$ hollow microtube; (g) Dynamic response transient of $\mathrm{ZnFe}_{2} \mathrm{O}_{4}$ hollow microsphere to different concentrations of acetone at $215{ }^{\circ} \mathrm{C}$; (h) The relationship between the responses of $\mathrm{SnO}_{2}$ microtubes sensor and $\mathrm{HCHO}$ concentration at $92{ }^{\circ} \mathrm{C}$. Reprinted from [133-138] with permission; (a) [133] Copyright (2016) Elsevier; (b) [134] Copyright (2016) American Chemical Society; (c,d) [135,136] Copyright $(2017,2014)$ Elsevier; (e,g) [137] Copyright (2015) American Chemical Society; (f,h) [138] Copyright (2017) Elsevier.

In addition, Figure $10 \mathrm{~g}$, h showed the sensing properties of $\mathrm{ZnFe}_{2} \mathrm{O}_{4}$ hollow microspheres and $\mathrm{SnO}_{2}$ hollow microtubes, respectively. It could be seen that the distinctive structure was fully adopted 
in the gas sensors, and the gas sensor performance was improved to obtain high responses and low detection limits. Recently, the gas-sensing performances hollow structures have been reported in a vast amount of publications, as shown in Table 4, but researchers are still eager to synthesize novel hollow structures to further improve the performance of gas sensors. Furthermore, the hollow nanostructures can offer an additional opportunity to adjust the characteristics by controlling the morphological parameters of crystal size, shell thickness and hole diameter.

Table 4. Summary of the gas-sensing performances of hollow structures to different gases.

\begin{tabular}{|c|c|c|c|c|c|c|c|c|c|}
\hline Morphology & Gases & Materials & $\begin{array}{l}\text { Conc. } \\
\text { (ppm) }\end{array}$ & $\begin{array}{c}\text { LOD } \\
\text { (ppm) }\end{array}$ & $\begin{array}{l}\text { Temp. } \\
\left({ }^{\circ} \mathrm{C}\right)\end{array}$ & $\tau_{\text {res }}(s)$ & $\tau_{\text {rec }}(\mathrm{s})$ & Resp. & Ref. \\
\hline hollow sphere & acetone & $\mathrm{TiO}_{2}$ & 100 & NA & 320 & NA & NA & $6.9^{\mathrm{a}}$ & [139] \\
\hline hollow sphere & methanol & $\alpha-\mathrm{Fe}_{2} \mathrm{O}_{3}$ & 10 & 1 & 280 & 8 & 9 & $25^{\mathrm{a}}$ & [140] \\
\hline hollow sphere & $\mathrm{NO}_{2}$ & $\mathrm{WO}_{3}$ & 0.1 & NA & 140 & 90 & 400 & $18^{\mathrm{b}}$ & [141] \\
\hline hollow sphere & $\mathrm{NO}_{2}$ & $\mathrm{WO}_{3}$ & 1 & 0.04 & 100 & 237 & 88 & $89^{b}$ & [142] \\
\hline hollow sphere & $\mathrm{HCHO}$ & $\mathrm{SnO}_{2}$ & 200 & NA & 300 & NA & NA & $9^{a}$ & [143] \\
\hline hollow sphere & ethanol & $\mathrm{ZnSnO}_{3}$ & 5 & NA & 280 & NA & NA & $4.5^{\mathrm{a}}$ & [144] \\
\hline hollow sphere & ethanol & $\mathrm{SnO}_{2}$ & 200 & NA & 260 & 10 & 8 & $274.5^{\mathrm{a}}$ & [145] \\
\hline multi-shelled hollow sphere & acetone & $\mathrm{SnO}_{2}$ & 200 & NA & 200 & 10 & 12 & $153^{a}$ & [146] \\
\hline hollow nanofiber & n-propanol & $\mathrm{CuO}$ & 100 & 1 & 200 & 19.18 & 63 & $4.66^{\mathrm{b}}$ & [147] \\
\hline hollow nanosheet & acetone & $\mathrm{SnO}_{2}$ & 50 & NA & 300 & 0.9 & 5.8 & $18.3^{\mathrm{a}}$ & [148] \\
\hline hollow cauliflower-like & $\mathrm{CO}$ & $\mathrm{WO}_{3}$ & 300 & NA & 270 & NA & NA & $41.9^{\mathrm{a}}$ & [149] \\
\hline hollow six-sided pyramids & ethanol & $\mathrm{ZnO}$ & 200 & NA & 240 & 11 & 9 & $187^{\mathrm{a}}$ & [150] \\
\hline hollow polyhedrons & acetone & $\mathrm{ZnSnO}_{3}$ & 50 & NA & 240 & 17 & 10 & $12.48^{\mathrm{a}}$ & [151] \\
\hline
\end{tabular}

The sensing performance of gas sensors can be improved though controlling the growth of a semiconductor oxide into a special morphology, so novel hollow structure morphologies can be introduced, such as flower-like, hollowed-out and microcubes. These particular architectures, which can provide good accessibility and more active sites for gas adsorption/desorption, have unique advantages in gas-sensing applications. $\mathrm{Xu}$ et al. have prepared a hollow flower-like porous $\mathrm{In}_{2} \mathrm{O}_{3}$ nanostructure by a solvothermal method [152]. The flower-like nanostructure was composed of nanosheets, and the nanosheets consisted of abundant nanoparticles. These nanoparticles with nanosize quantum confinement effects formed many active sites that facilitated gas adsorption on the surface. The hollow structure provided more passageways for accelerating gas accessibility and transmission on the inner and outer surface of the $\mathrm{In}_{2} \mathrm{O}_{3}$ nanostructure, so a unique morphology is conducive to improving the sensing performance of semiconductor oxides.

Moreover, the hollowed-out structure can endow semiconductor oxides with distinct porous natures, contributing to performance improvements of the gas sensor. Due to their open diffusion channels, hollowed-out structures can afford more convenient pathways to gas molecules. For instance, Tan et al. have reported that the hollow $\mathrm{Co}_{3} \mathrm{O}_{4}$ microspheres assembled from nanosheets exhibited high response with a value of 38.8 to $100 \mathrm{ppm}$ ethanol due to the hollowed-out structure [153]. The hollowed-out structure could guarantee that large quantities of oxygen molecules and ethanol gases could permeate into the active sites on the entire surface and inner-surface. In addition, the hollowed-out $\mathrm{Co}_{3} \mathrm{O}_{4}$ microspheres presented ultrafast response and recovery time of $0.1 \mathrm{~s}$ and 0.7 $\mathrm{s}$. This was a rare instance, in which response and recovery time were both less than $1 \mathrm{~s}$. The ultrafast response/recovery speed was ascribed to the porous nanosheets and the nature of $\mathrm{Co}_{3} \mathrm{O}_{4}$. On the one hand, the porous nanosheets composed by interconnected nanoparticles have greater pore diameter than ethanol molecular clusters which endows them with higher permeability and faster electron transmission. On the other hand, $\mathrm{Co}_{3} \mathrm{O}_{4}$ has a high catalytic activity boosting reaction rate, therefore, the hollowed-out $\mathrm{Co}_{3} \mathrm{O}_{4}$ microspheres have an extraordinary gas-sensing performance.

Recently, researchers have taken an intense interest in the hollow microcube with well-defined interior voids. Compared to spheres with point-to-point contacting, microcubes with the face-to-face contacting increase contact area and improve performance of gas sensor. Zhang et al. reported that hollow $\mathrm{MoO}_{3}$ microcube exhibited obviously enhanced response to $100 \mathrm{ppm}$ ethanol with the value of about 78 and response/recovery time of $15 \mathrm{~s} / 5 \mathrm{~s}$ [154]. This was related to the advantages of large 
surface area resulting from the hollow microcubes. That is, more oxygen molecules absorbed on the surface of the microcubes in the air and reacted with ethanol, contributing to a high response value. Moreover, there was a wider conductive path when the captured free electrons were released to the $\mathrm{MoO}_{3}$ conduction band, which was ascribed to microcubes with face-to-face contact, so the $\mathrm{MoO}_{3}$ microcubes with a larger contact area displayed superior gas-sensing properties and faster reaction rates.

In addition, the gas response of hollow semiconductor oxides is also influenced by their morphological parameters. Thus, Li et al. have discussed the influence of the crystal size and the shell thickness on the gas-sensing performance of $\mathrm{SnO}_{2}$ hollow microspheres [155]. The obtained results indicated that the acetone sensing performance increased with the decrease of the crystal size and the shell thickness of the $\mathrm{SnO}_{2}$ hollow microspheres. The small crystal size and the thin shell thickness favored the adsorption and desorption of gas molecules on the surface, therefore, a controlled morphology can achieve an optimal gas-sensing performance.

However, these studies focus on the 3D nanostructure, but 1D nanostructures also can form a hollow interior space, and the hole diameter is one of factors influencing the gas-sensing performance of 1D hollow nanostructures. Compared with conventional solid fibers, hollow fibers have unique structural characteristics. In the hollow fibers, the hole diameter directly determines the area of the inner surface, thus changing the sensing performance. Accordingly, Katoch et al. discussed the influence of the hole diameter on the sensing performance of $\mathrm{ZnO}$ hollow fibers. The gas-sensing performance of hollow nanofibers can be improved by tuning the hole diameter. It was reported that the specific surface area increased with the decrease of the hole diameter, which was responsible for the performance of the gas sensors. In addition, $\mathrm{ZnO}$ hollow fibers with smaller hole diameter are much more conducive to obtaining high performances [156].

\section{Core-Shell Structure of Semiconductor Oxide for Gas-Sensing Performance}

Core-shell semiconductor oxide structures, as a kind of very potential sensing material, have been gaining extensive attention for gas sensors. The unique nanostructure plays a key role in the performance of the gas sensor. The core-shell structures are divided into seven types, depending on the type of core and shell [157]. Core-shell structures have various gas-sensing performances because of the different configurations based on the core and the shell. In addition, core-shell nanostructures ensure a huge surface area and rapid gas diffusion, which is preferable to improve the gas-sensing characteristics of the sensor. Recently, many studies based on core-shell structure materials and their gas-sensing performances have been reported, as shown in Figure 11 [158-161]. As can be seen in some studies that contrast the responses, it is quite obvious that the gas-sensing performance is significantly improved with the introduction of core-shell structures. That is to say, the morphological characteristics influence the performance of gas sensors, so it is very necessary to summarize the sensing performances of core-shell structures, as shown in Table 5.

Table 5. Summary of the sensing performances of core-shell structures to different gases.

\begin{tabular}{|c|c|c|c|c|c|c|c|c|c|}
\hline Morphology & Gases & Materials & Conc. (ppm) & LOD (ppm) & Temp. $\left({ }^{\circ} \mathrm{C}\right)$ & $\tau_{\text {res }}(\mathrm{s})$ & $\tau_{\text {rec }}(s)$ & Resp. & Ref. \\
\hline core-shell nanoparticle & $\mathrm{CO}$ & $\mathrm{Au} / \mathrm{SnO}_{2}$ & 200 & NA & 200 & NA & NA & $1.3^{\mathrm{a}}$ & [162] \\
\hline core-shell nanoparticle & $\mathrm{O}_{3}$ & $\mathrm{Au} / \mathrm{TiO}_{2}$ & 2.5 & 0.36 & RT & 5 & 24 & $3.27^{\mathrm{a}}$ & [163] \\
\hline core-shell nanofiber & TMA & $\mathrm{In}_{2} \mathrm{O}_{3} / \mathrm{SnO}_{2}$ & 10 & NA & 280 & 3 & 32 & $7.11^{\mathrm{a}}$ & [164] \\
\hline core-shell nanofiber & $\mathrm{HCHO}$ & $\mathrm{NiO} / \alpha-\mathrm{Fe}_{2} \mathrm{O}_{3}$ & 50 & 1 & 240 & 2 & 9 & $12.8^{\mathrm{a}}$ & [165] \\
\hline core-shell nanofiber & ethanol & $\mathrm{SiO}_{2} / \mathrm{SnO}_{2}$ & 200 & NA & NA & 13 & 16 & $37^{\mathrm{a}}$ & [166] \\
\hline core-shell nanofiber & ethanol & $\mathrm{ZnO} / \mathrm{SnO}_{2}$ & 100 & NA & 200 & 75 & 12 & $392.29^{a}$ & [167] \\
\hline core-shell nanowire & $\mathrm{NO}_{2}$ & $\mathrm{~W}_{18} \mathrm{O}_{49} / \mathrm{TiO}_{2}$ & 5 & NA & RT & NA & NA & $36.5^{\mathrm{a}}$ & [168] \\
\hline core-shell nanosphere & $\mathrm{H}_{2} \mathrm{~S}$ & $\mathrm{CuO} / \mathrm{NiO}$ & 100 & NA & 260 & 18 & 29 & $47.6^{\mathrm{b}}$ & [169] \\
\hline core-shell nanosphere & $\mathrm{NH}_{3}$ & $\mathrm{Co}_{3} \mathrm{O}_{4} / \mathrm{SnO}_{2}$ & 50 & NA & 200 & 4 & 17 & $13.6^{\mathrm{a}}$ & [170] \\
\hline yolk-shell nanoparticle & ethanol & $\mathrm{Pd} / \mathrm{In}_{2} \mathrm{O}_{3}$ & 5 & $\mathrm{NA}$ & 350 & NA & NA & $159.02^{\mathrm{a}}$ & [171] \\
\hline yolk-shell nanoparticle & acetone & $\mathrm{Au} / \mathrm{ZnO}$ & 10 & 0.05 & 280 & 15 & 12 & $43^{\mathrm{a}}$ & [172] \\
\hline yolk-shellnanostructure & $\mathrm{H}_{2} \mathrm{~S}$ & $\mathrm{MoO}_{3} / \mathrm{Fe}_{2}\left(\mathrm{MoO}_{4}\right)_{3}$ & 1 & NA & 70 & 20 & 70 & $1.7^{\mathrm{a}}$ & [173] \\
\hline yolk-shellnanosphere & acetone & $\mathrm{ZnFe}_{2} \mathrm{O}_{4}$ & 50 & 0.5 & 200 & NA & NA & $28.5^{\mathrm{a}}$ & [174] \\
\hline
\end{tabular}



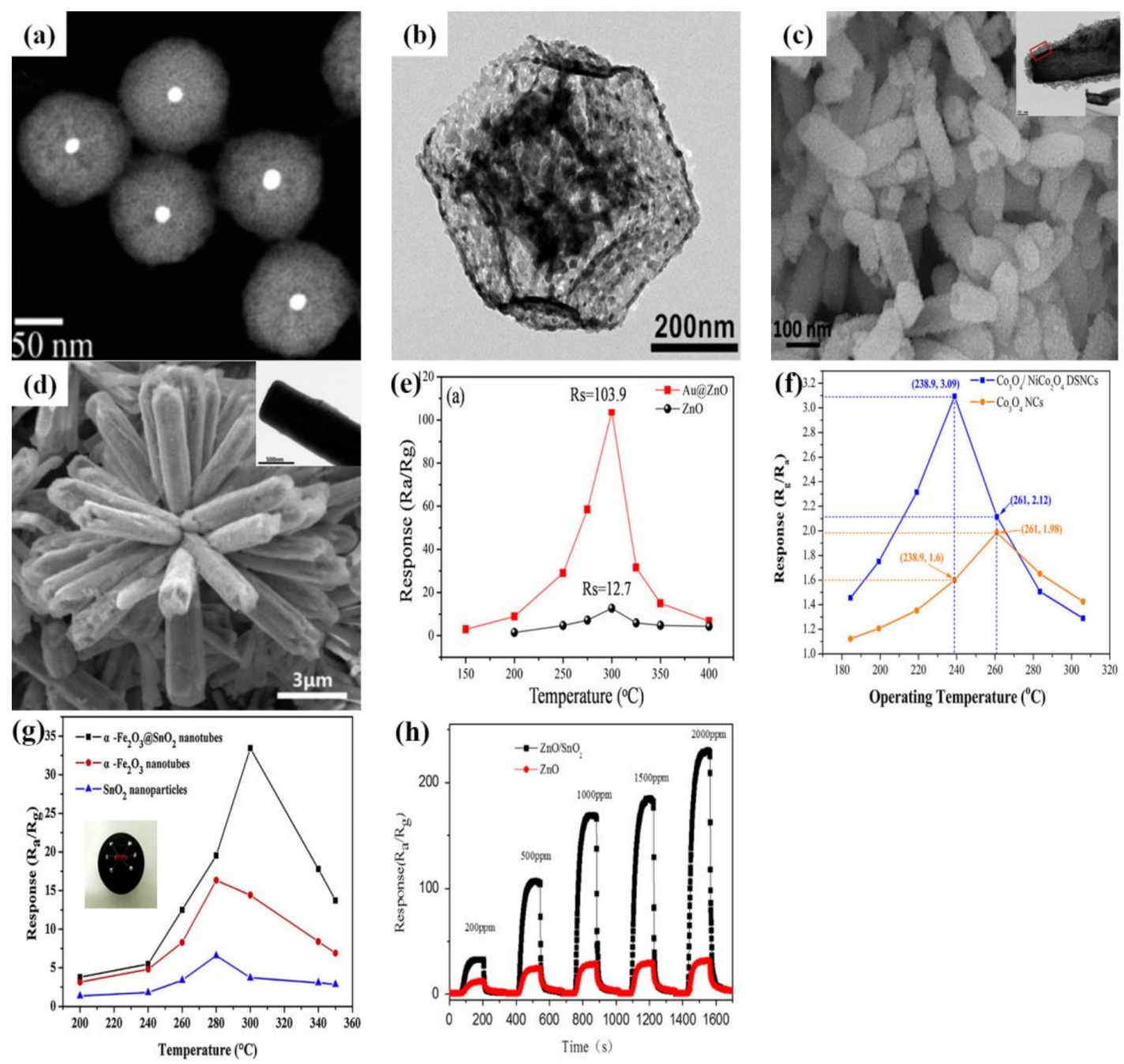

Figure 11. (a) TEM image of Au@ZnO core-shell nanoparticles; (b) TEM image of $\mathrm{Co}_{3} \mathrm{O}_{4} / \mathrm{NiCo}_{2} \mathrm{O}_{4}$ core-shell nanocages; (c) SEM and TEM images of $\alpha-\mathrm{Fe}_{2} \mathrm{O}_{3} @ \mathrm{SnO}_{2}$ core-shell nanotubes; (d) SEM and TEM images of $\mathrm{ZnO} / \mathrm{SnO}_{2}$ core-shell nanorods; (e) Response of sensors based on the pure $\mathrm{ZnO}$ and $\mathrm{Au} / \mathrm{ZnO}$ core-shell nanoparticles to $100 \mathrm{ppm}$ of $\mathrm{H}_{2}$; (f) Response of sensors based on the $\mathrm{Co}_{3} \mathrm{O}_{4} / \mathrm{NiCo}_{2} \mathrm{O}_{4}$ core-shell nanocages and $\mathrm{Co}_{3} \mathrm{O}_{4}$ nanocages to $100 \mathrm{ppm}$ acetone; (g) Variations of response $\left(\mathrm{R}_{\mathrm{a}} / \mathrm{R}_{\mathrm{g}}\right)$ for the $\alpha-\mathrm{Fe}_{2} \mathrm{O}_{3} / \mathrm{SnO}_{2}$ heterostructures, the pristine $\alpha-\mathrm{Fe}_{2} \mathrm{O}_{3}$ nanotubes and the $\mathrm{SnO}_{2}$ nanoparticles to $100 \mathrm{ppm}$ acetone at different operating temperatures; (h) the transient response curves of sensors (pure $\mathrm{ZnO}$ and $\mathrm{ZnO} / \mathrm{SnO}_{2}$ ) with different concentration of ethanol at $300{ }^{\circ} \mathrm{C}$. Reprinted from [158-161] with permission; (a,e) [158] Copyright (2015) American Chemical Society; (b,f) [159] Copyright (2017) Elsevier; (c,g) [160] Copyright (2015) Elsevier; (d,h) [161] Copyright (2015) Elsevier.

The yolk-shell nanostructure is considered to be a specific kind of core-shell structure with a unique core@void@shell configuration. It provides more space for gas sensor applications due to the particularity of the structure. Since then, more and more researchers have paid attention to the preparation of yolk-shell nanostructures in order to obtain superior gas-sensing performance. For instance, Wang et al. have prepared solid, hollow, yolk-shell $\alpha-\mathrm{Fe}_{2} \mathrm{O}_{3}$ nanospheres by adjusting the reaction time [175]. The yolk-shell $\alpha-\mathrm{Fe}_{2} \mathrm{O}_{3}$ nanospheres exhibited better gas-sensing performance to ethanol than the other two nanospheres due to the unique nanostructure. This was related to the inner shell having a hollow structure, leading to the adsorption of more gas molecules in the gas-sensing reaction. Moreover, the void between the outer shell and the inner core ensured that 
$\alpha-\mathrm{Fe}_{2} \mathrm{O}_{3}$ nanospheres had a larger specific surface area. In the meantime, the porous outer shell could accelerate the permeability and diffusion of ethanol gases, thus enhancing the sensing performance.

More recently, Kim et al. have fabricated an enhanced gas sensor based on triple-shelled $\mathrm{WO}_{3}$ yolk-shell spheres [176]. In order to verify the excellent gas-sensing performance of multi-shelled $\mathrm{WO}_{3}$ yolk-shell spheres, dense $\mathrm{WO}_{3}$ spheres and double-shelled yolk-shell $\mathrm{WO}_{3}$ spheres were also prepared for the detection of $\mathrm{NO}_{2}$ gas. The sensor response towards $50 \mathrm{ppb} \mathrm{NO}_{2}$ at an operating temperature of $100{ }^{\circ} \mathrm{C}$ was increased from 8.9 for dense $\mathrm{WO}_{3}$ spheres and 57.3 for double-shelled yolk-shell $\mathrm{WO}_{3}$ spheres to 100 for triple-shelled $\mathrm{WO}_{3}$ yolk-shell spheres. After the comparison, it could be known that the response of yolk-shell spheres was significantly higher than that of dense spheres due to the increased gas accessibility. In addition, the thin and multi-shelled yolk-shell morphologies resulted in higher permeability compared with double-shelled yolk-shell spheres, contributing to the enhanced response to ppb level $\mathrm{NO}_{2}$. Thus, different types of structural characteristics may account for the response differences, revealing that a unique morphology and structure can be very helpful in enhancing the gas response. Since then, Bing et al. have prepared unique $\mathrm{SnO}_{2}$ yolk-shell cuboctahedra with accessible surface [177]. The nonspherical yolk-shell structures exhibited a high response value of 28.6 and a fast response speed of $1.8 \mathrm{~s}$ towards $20 \mathrm{ppm}$ toluene at $250{ }^{\circ} \mathrm{C}$ due to the high surface area as well as their penetrable shells and cores. Besides, the face-to-face contacting possessed a broader conductive channel for free electrons, leading to a lower height of the potential barrier. As a result, a high response value and a rapid response speed could be obtained simultaneously.

In general, core-shell structures are formed by two materials, combining the advantages of each other. $\mathrm{Li}$ et al. have prepared $\mathrm{Au} / \mathrm{In}_{2} \mathrm{O}_{3}$ core-shell microstructures, where the $\mathrm{Au}$ core was surrounded by a $\mathrm{In}_{2} \mathrm{O}_{3}$ shell layer with a thickness of about $50 \mathrm{~nm}$ [178]. According to the comparative gas response to $\mathrm{HCHO}$ gas between $\mathrm{Au} / \mathrm{In}_{2} \mathrm{O}_{3}$ core-shell microstructures and pure $\mathrm{In}_{2} \mathrm{O}_{3}$ spheres, it was indicated that the $\mathrm{Au} / \mathrm{In}_{2} \mathrm{O}_{3}$ composites showed enhanced sensing performance. The improved response was explained on the basis of Au nanoparticles with exceptional catalytic activities. What's more, the loose and porous $\operatorname{~} n_{2} \mathrm{O}_{3}$ shell could be boosted to increase the accessibilities of Au nanoparticles to $\mathrm{HCHO}$ gas molecules thus potentially triggering an increase in the response characteristics. More importantly, the formation of the metal-semiconductor junction induced a broader electron depletion layer and greater band bending compared with pure $\operatorname{In}_{2} \mathrm{O}_{3}$ spheres, so when exposed to $\mathrm{HCHO}$ gas, more captured electrons would be released back to the conduction band, leading to a sensing performance enhancement.

As we all know, high specific surface area signifies the production of more absorbed oxygen species in the gas-sensing reaction that subsequently interact with target gases. Qu et al. have prepared $\mathrm{ZnO} / \mathrm{ZnCo}_{2} \mathrm{O}_{4}$ core-shell nanocages to detect xylene [179]. The $\mathrm{ZnO} / \mathrm{ZnCo}_{2} \mathrm{O}_{4}$ core-shell nanocages exhibited remarkably enhanced gas-sensing performance in comparison with the single component semiconductor oxide, which was ascribed to the novel nanostructure with high specific surface area and the formation of a hole depletion layer caused by the Fermi level difference between $\mathrm{ZnO}$ and $\mathrm{ZnCo}_{2} \mathrm{O}_{4}$. In addition, the synergistic effect of $\mathrm{ZnO}$ and $\mathrm{ZnCo}_{2} \mathrm{O}_{4}$ as well as the catalytic effect of the cobalt oxides could improve the chemical activity of xylene gas, resulting in the increased response.

\section{The Effect of Catalyst on Gas-Sensing Performance}

Although the morphologies of semiconductor oxides have an effect on the gas-sensing properties, it is not enough. The improvement of the gas-sensing properties is also related to the use of additives in the semiconductor oxides. Thus, additives are often introduced into semiconductor oxides as sensitizers or promoters in order to improve gas-sensing performances due to their exceptional activities. It is noteworthy that the surface morphology of semiconductor oxide is also changed by adding a catalyst, thus forming a more advantageous surface for gas-sensing reactions. Consequently, the effective combination of morphology and catalysis will be beneficial to obtain a superior gas sensor with higher response, faster response speed, lower power consumption and lower limit of detection. 
Commonly, a variety of strategies including element doping [180], noble metal loading [31] and surface functionalization [181] were used to obtain further enhanced gas-sensing performances. Among them, element doping is regarded as a facile and effective route to enhance gas-sensing performances. Han et al. have investigated the gas-sensing performances of Ce-doped $\operatorname{In}_{2} \mathrm{O}_{3}$ porous nanospheres toward $100 \mathrm{ppm}$ methanol compared to pure $\operatorname{In}_{2} \mathrm{O}_{3}$ samples [182]. It was found that Ce-doped $\mathrm{In}_{2} \mathrm{O}_{3}$ porous nanospheres exhibited enhanced sensing performance due to the incorporation of the elemental Ce. The doping with Ce could greatly reduce the crystallite size in order to increase the specific surface area, forming an advantageous morphology that may help increase the electron transport. In addition, Ce ions released electrons back into the conduction band and the electronic properties are influenced by increasing the concentration of free electrons. Accordingly, Ce-doped $\mathrm{In}_{2} \mathrm{O}_{3}$ porous nanospheres are observed to give better gas-sensing performance than undoped $\mathrm{In}_{2} \mathrm{O}_{3}$ samples. Semiconductor oxides as sensitizers are also incorporated into semiconducting oxides, which induce more sensor selectivity to the target gas and reduce the power consumption. For example, Nasrabadi et al. have prepared $\mathrm{Gd}_{2} \mathrm{O}_{3}$-doped $\mathrm{SnO}_{2}$ nanoparticles that showed a maximum response at $150{ }^{\circ} \mathrm{C}$, whereas pure $\mathrm{SnO}_{2}$ nanoparticles had the highest response at $250{ }^{\circ} \mathrm{C}$ [183]. Moreover, $\mathrm{Gd}_{2} \mathrm{O}_{3}$-doped $\mathrm{SnO}_{2}$ nanoparticles also exhibited ultrahigh selectivity to ethanol and the response toward ethanol was 355- and 1641-fold greater than the responses toward $\mathrm{CH}_{4}$ and $\mathrm{CO}$, respectively. The catalytic oxidation properties arise from adding $\mathrm{Gd}_{2} \mathrm{O}_{3}$, which endowed $\mathrm{Gd}_{2} \mathrm{O}_{3}$-doped $\mathrm{SnO}_{2}$ nanoparticles surface with higher activities, so a higher amount of oxygen was adsorbed on the surface, inducing an improved response to ethanol.

Loading a noble metal catalyst $(\mathrm{Pt}, \mathrm{Pd}, \mathrm{Au}, \mathrm{Ag})$ is also a very effective way of improving gas-sensing performance [184,185]. Wang et al. have prepared Pt-loaded mesoporous $\mathrm{WO}_{3}$ and mesoporous $\mathrm{WO}_{3}$ for comparison [186]. The sensor response was increased from 6.72 for pure mesoporous $\mathrm{WO}_{3}$ to 13.61 for Pt-loaded mesoporous $\mathrm{WO}_{3}$. Thus, the sensor made of Pt-loaded mesoporous $\mathrm{WO}_{3}$ showed a strengthened gas-sensing performance toward ammonia compared to those made from pure mesoporous $\mathrm{WO}_{3}$, owing to the matrix and the catalyst. The matrix provided a mesoporous structure for promoting gas transport and diffusion, while, the catalytic properties of Pt additives accelerated the adsorption/desorption reactions of oxygen and ammonia gas. This indicated that the loaded noble metal had a significant impact on the gas-sensing performance. In general, noble metal loaded means mono-noble metal loaded, and the effect of multi-metallic loading has rarely been reported. Recently Fan et al. [187] prepared $\mathrm{Pt} / \mathrm{Au}$ bimetallic nanoparticles loaded on $\mathrm{ZnO}$ nanorods, which exhibited better response to $\mathrm{H}_{2}$ than Pt-loaded $\mathrm{ZnO}$ and $\mathrm{Au}$-loaded $\mathrm{ZnO}$, owing to the effect of the bimetallic nanoparticles containing two mono-metal analogues. The bimetallic nanoparticles showed enhanced catalytic performances resulting from the synergistic effect of the two mono-metal nanoparticles, leading to improved adsorption properties and superior sensing properties.

In addition, it is worth mentioning that the gas-sensing performance can be substantially enhanced by surface functionalization. To investigate the effect of surface functionalization, Koo et al. have prepared $\mathrm{PdO}$ nanoparticles functionalized $\mathrm{Co}_{3} \mathrm{O}_{4}$ hollow nanocages by utilizing MOF as a template, as shown in Figure 12a,b. PdO nanoparticle-functionalized $\mathrm{Co}_{3} \mathrm{O}_{4}$ hollow nanocages displayed significantly enhanced acetone sensing performance owing to the effects of the hollow and porous structure as well as the functionalization by the nanoscale catalyst, which was superior to $\mathrm{PdO} / \mathrm{Co}_{3} \mathrm{O}_{4}$ powders, $\mathrm{Co}_{3} \mathrm{O}_{4}$ hollow nanocages and $\mathrm{Co}_{3} \mathrm{O}_{4}$ powders, as shown in Figure 12c,d. The increase in the surface area could lead to the increment of reaction sites due to the unique structure. Moreover, $\mathrm{PdO}$ nanoparticles reacted with acetone molecules and released additional electrons to $\mathrm{Co}_{3} \mathrm{O}_{4}$, resulting in an increase in the resistance of the sensor [188]. 


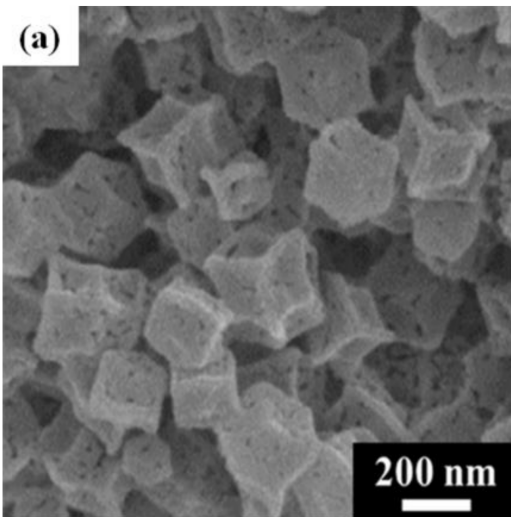

(c)

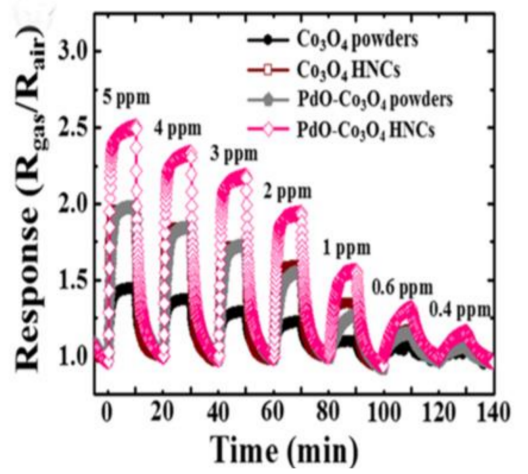

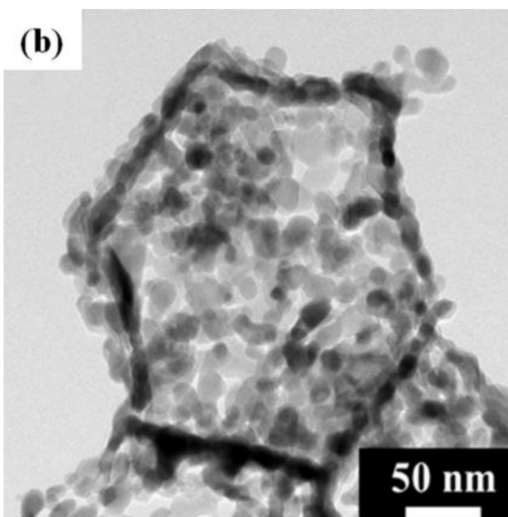

(d)

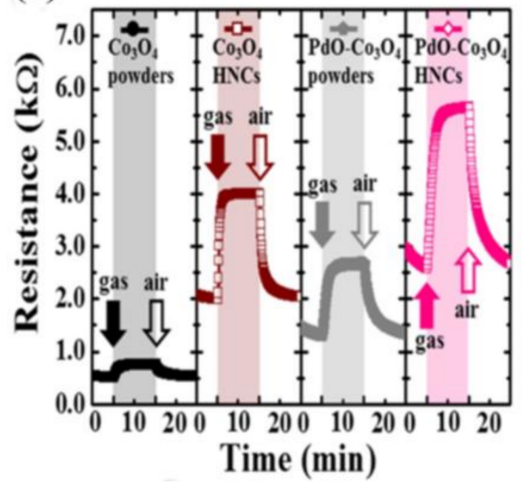

Figure 12. (a) SEM images of $\mathrm{PdO}-\mathrm{Co}_{3} \mathrm{O}_{4}$ hollow nanocages; (b) TEM images of $\mathrm{PdO} / \mathrm{Co}_{3} \mathrm{O}_{4}$ nanocages; (c) Dynamic acetone sensing transient properties of $\mathrm{Co}_{3} \mathrm{O}_{4}$ powders, $\mathrm{Co}_{3} \mathrm{O}_{4}$ hollow nanocages, $\mathrm{PdO} / \mathrm{Co}_{3} \mathrm{O}_{4}$ powders, and $\mathrm{PdO} / \mathrm{Co}_{3} \mathrm{O}_{4}$ hollow nanocages in the concentration range of 0.4-5.0 ppm; (d) Dynamic resistance transition toward 5 ppm of acetone molecules. Reprinted from [188] with permission. Copyright (2017) American Chemical Society.

\section{Conclusions and Perspectives}

With the continuing deterioration of the environment and peoples' increasing awareness of the importance of protecting the environment, researchers are constantly looking for high performance gas sensors to detect deleterious gases. The morphologies of semiconductor oxides affect the properties of gas sensors, therefore, it is necessary to carry out an overview of different morphologies and their gas-sensing performances. This review gives a classification of morphologies, whereby semiconductor oxides can be defined as zero-dimensional, one-dimensional, two-dimensional and three-dimensional. The results indicate that semiconductor oxides with different morphologies each have their own unique advantages, contributing to the improvement of gas-sensing properties. Moreover, hollow structure and core-shell structure materials exhibit high gas-sensing performances due to their large specific surface areas, which allow the inner and outer surface to absorb more target gases.

Although sensors have been developed in recent years, the sensors with high performances still needs further develop by controlling the morphology and the nanostructure of semiconductor oxides. In the field of semiconducting oxide gas sensors, it can be predicted that potential strategies for enhancing the gas-sensing performance should involve several aspects: (1) novel semiconductor oxide nanostructures which may achieve ultrasensitive and ultraselective detection of gases; (2) hollow hierarchical of semiconductor oxides which provide a higher specific surface area to obtain more active sites for gas diffusion; (3) core-shell semiconductor oxide nanostructures that possess heterostructures, which can be regarded as a novel form of potential sensing materials. All this together suggests that the improvement of the performance of gas sensors will undoubtedly continue to be of great importance in the future. 
Acknowledgments: This work was supported by the National Key R\&D Program of China (2017YFC0804105), the National Foundation of China (Grant Nos. 41722405, 2011YQ03113, 20140204022GX, and 41374075), the Fundamental Research Funds for the Central Universities and the Education Department of Jilin Province (No. 440020032122).

Author Contributions: Tingting Lin and Xin Lv participated in the selection of papers and contributed to the writing of the paper. Xin Lv and Shuang Li collected, disposed and analyzed the data. Tingting Lin and Qingji Wang helped to modify this manuscript.

Conflicts of Interest: The authors declare no conflict of interest.

\section{References}

1. Wang, H.L.; Nie, L.; Li, J.; Wang, Y.F.; Wang, G.; Wang, J.H.; Hao, Z.P. Characterization and assessment of volatile organic compounds (VOCs) emissions from typical industries. Chin. Sci. Bull. 2013, 58, 724-730. [CrossRef]

2. Fine, G.F.; Cavanagh, L.M.; Afonja, A.; Binions, R. Metal Oxide Semi-Conductor Gas Sensors in Environmental Monitoring. Sensors 2010, 10, 5469-5502. [CrossRef] [PubMed]

3. Wetchakun, K.; Samerjai, T.; Tamaekong, N.; Liewhiran, C.; Siriwong, C.; Kruefu, V.; Wisitsoraat, A.; Tuantranont, A.; Phanichphant, S. Semiconducting metal oxides as sensors for environmentally hazardous gases. Sens. Actuators B Chem. 2011, 160, 580-591. [CrossRef]

4. Mirzaei, A.; Leonardi, S.G.; Neri, G. Detection of hazardous volatile organic compounds (VOCs) by metal oxide nanostructures-based gas sensors: A review. Ceram. Int. 2016, 42, 15119-15141. [CrossRef]

5. Llobet, E.; Brunet, J.; Pauly, A.; Ndiaye, A.; Varenne, C. Nanomaterials for the Selective Detection of Hydrogen Sulfide in Air. Sensors 2017, 17, 391. [CrossRef] [PubMed]

6. Gu, D.; Li, X.G.; Zhao, Y.Y.; Wang, J. Enhanced $\mathrm{NO}_{2}$ sensing of $\mathrm{SnO}_{2} / \mathrm{SnS}_{2}$ heterojunction based sensor. Sens. Actuators B Chem. 2017, 244, 67-76. [CrossRef]

7. Wang, Q.J.; Wang, C.; Sun, H.B.; Sun, P.; Wang, Y.Z.; Lin, J.; Lu, G.Y. Microwave assisted synthesis of hierarchical $\mathrm{Pd} / \mathrm{SnO}_{2}$ nanostructures for $\mathrm{CO}$ gas sensor. Sens. Actuators B Chem. 2016, 222, 257-263. [CrossRef]

8. Ma, L.T.; Fan, H.Q.; Tian, H.L.; Fang, J.W.; Qian, X.Z. The n-ZnO/n- $\operatorname{In}_{2} \mathrm{O}_{3}$ heterojunction formed by a surface-modification and their potential barrier-control in methanal gas sensing. Sens. Actuators $B$ Chem. 2016, 222, 508-516. [CrossRef]

9. Kheel, H.; Sun, G.-J.; Lee, J.K.; Lee, S.; Dwivedi, R.P.; Lee, C. Enhanced $\mathrm{H}_{2} \mathrm{~S}$ sensing performance of $\mathrm{TiO}_{2}$-decorated $\alpha-\mathrm{Fe}_{2} \mathrm{O}_{3}$ nanorod sensors. Ceram. Int. 2016, 42, 18597-18604. [CrossRef]

10. Perrozzi, F.; Emamjomeh, S.M.; Paolucci, V.; Taglieri, G.; Ottaviano, L.; Cantalini, C. Thermal stability of WS flakes and gas sensing properties of $\mathrm{WS}_{2} / \mathrm{WO}_{3}$ composite to $\mathrm{H}_{2}, \mathrm{NH}_{3}$ and $\mathrm{NO}_{2}$. Sens. Actuators $B$ Chem. 2017, 243, 812-822. [CrossRef]

11. Dhahri, R.; Leonardi, S.G.; Hjiri, M.; Mir, L.E.; Bonavita, A.; Donato, N.; Iannazzo, D.; Neri, G. Enhanced performance of novel calcium/aluminum co-doped zinc oxide for $\mathrm{CO}_{2}$ sensors. Sens. Actuators B Chem. 2017, 239, 36-44. [CrossRef]

12. Wang, B.; Jin, H.T.; Zheng, Z.Q.; Zhou, Y.H.; Gao, C. Low-temperature and highly sensitive $\mathrm{C}_{2} \mathrm{H}_{2}$ sensor based on $\mathrm{Au}$ decorated $\mathrm{ZnO} / \mathrm{In}_{2} \mathrm{O}_{3}$ belt-tooth shape nano-heterostructures. Sens. Actuators B Chem. 2017, 244, 344-356. [CrossRef]

13. Wang, Q.J.; Li, X.; Liu, F.M.; Sun, Y.F.; Wang, C.; Li, X.W.; Sun, P.; Lin, J.; Lu, G.Y. Three-dimensional flake-flower $\mathrm{Co} / \mathrm{Sn}$ oxide composite and its excellent ethanol sensing properties. Sens. Actuators B Chem. 2016, 230, 17-24. [CrossRef]

14. Liu, H.Y.; Yang, W.; Wang, M.X.; Xiao, L.; Liu, S.T. Fabrication of lotus-like Au@TiO 2 nanocomposites with enhanced gas-sensing properties. Sens. Actuators B Chem. 2016, 236, 490-498. [CrossRef]

15. Miller, D.R.; Williams, R.E.; Akbar, S.A.; Morris, P.A.; McComb, D.W. STEM-Cathodoluminescence of $\mathrm{SnO}_{2}$ nanowires and powders. Sens. Actuators B Chem. 2017, 240, 193-203. [CrossRef]

16. Karthik, T.V.; Olvera Mde, L.; Maldonado, A.; Gomez Pozos, H. CO Gas Sensing Properties of Pure and $\mathrm{Cu}$-Incorporated $\mathrm{SnO}_{2}$ Nanoparticles: A Study of Cu-Induced Modifications. Sensors 2016, 16, 1283. [CrossRef] [PubMed]

17. Huber, F.; Riegert, S.; Madel, M.; Thonke, $\mathrm{K} . \mathrm{H}_{2} \mathrm{~S}$ sensing in the ppb regime with zinc oxide nanowires. Sens. Actuators B Chem. 2017, 239, 358-363. [CrossRef] 
18. Kim, N.H.; Choi, S.J.; Kim, S.J.; Cho, H.J.; Jang, J.S.; Koo, W.T.; Kim, M.; Kim, I.D. Highly sensitive and selective acetone sensing performance of $\mathrm{WO}_{3}$ nanofibers functionalized by $\mathrm{Rh}_{2} \mathrm{O}_{3}$ nanoparticles. Sens. Actuators B Chem. 2016, 224, 185-192. [CrossRef]

19. Yan, H.H.; Song, P.; Zhang, S.; Zhang, J.; Yang, Z.X.; Wang, Q. Au nanoparticles modified $\mathrm{MoO}_{3}$ nanosheets with their enhanced properties for gas sensing. Sens. Actuators B Chem. 2016, 236, 201-207. [CrossRef]

20. Liu, J.Y.; Wang, C.; Yang, Q.Y.; Gao, Y.; Zhou, X.; Liang, X.S.; Sun, P.; Lu, G.Y. Hydrothermal synthesis and gas-sensing properties of flower-like $\mathrm{Sn}_{3} \mathrm{O}_{4}$. Sens. Actuators B Chem. 2016, 224, 128-133. [CrossRef]

21. Wang, Q.J.; Li, X.; Liu, F.M.; Liu, C.; Su, T.; Lin, J.; Sun, P.; Sun, Y.F.; Liu, F.M.; Lu, G.Y. The enhanced CO gas sensing performance of $\mathrm{Pd} / \mathrm{SnO}_{2}$ hollow sphere sensors under hydrothermal conditions. RSC Adv. 2016, 6, 80455-80461. [CrossRef]

22. Kim, J.H.; Kim, H.W.; Kim, S.S. Ultra-sensitive benzene detection by a novel approach: Core-shell nanowires combined with the Pd-functionalization. Sens. Actuators B Chem. 2017, 239, 578-585. [CrossRef]

23. Shankar, P.; Rayappan, J.B.B. Gas sensing mechanism of metal oxides: The role of ambient atmosphere, type of semiconductor and gases-A review. Sci. Lett. J. 2015, 4, 126.

24. Sun, Y.F.; Liu, S.B.; Meng, F.L.; Liu, J.Y.; Jin, Z.; Kong, L.T.; Liu, J.H. Metal oxide nanostructures and their gas sensing properties: A review. Sensors 2012, 12, 2610-2631. [CrossRef] [PubMed]

25. Wang, C.X.; Yin, L.W.; Zhang, L.Y.; Xiang, D.; Gao, R. Metal oxide gas sensors: Sensitivity and influencing factors. Sensors 2010, 10, 2088-2106. [CrossRef] [PubMed]

26. Korotcenkov, G.; Cho, B.K. Metal oxide composites in conductometric gas sensors: Achievements and challenges. Sens. Actuators B Chem. 2017, 244, 182-210. [CrossRef]

27. Mane, A.A.; Moholkar, A.V. Effect of film thickness on $\mathrm{NO}_{2}$ gas sensing properties of sprayed orthorhombic nanocrystalline $\mathrm{V}_{2} \mathrm{O}_{5}$ thin films. Appl. Surf. Sci. 2017, 416, 511-520. [CrossRef]

28. Rumyantseva, M.N.; Makeeva, E.A.; Badalyan, S.M.; Zhukova, A.A.; Gaskov, A.M. Nanocrystalline $\mathrm{SnO}_{2}$ and $\operatorname{In}_{2} \mathrm{O}_{3}$ as materials for gas sensors: The relationship between microstructure and oxygen chemisorption. Thin Solid Films 2009, 518, 1283-1288. [CrossRef]

29. Qiao, P.Y.; Zhang, L.X.; Zhu, M.Y.; Yin, Y.Y.; Zhao, Z.W.; Sun, H.N.; Dong, J.Y.; Bie, L.J. Acetylene sensing enhancement of mesoporous $\mathrm{ZnO}$ nanosheets with morphology and defect induced structural sensitization. Sens. Actuators B Chem. 2017, 250, 189-197. [CrossRef]

30. Sui, L.; Zhang, X.; Cheng, X.; Wang, P.; Xu, Y.; Gao, S.; Zhao, H.; Huo, L. Au-Loaded Hierarchical MoO 3 Hollow Spheres with Enhanced Gas-Sensing Performance for the Detection of BTX (Benzene, Toluene, And Xylene) and the Sensing Mechanism. ACS Appl. Mater. Interfaces 2017, 9, 1661-1670. [CrossRef] [PubMed]

31. Bing, Y.; Zeng, Y.; Feng, S.; Qiao, L.; Wang, Y.; Zheng, W. Multistep assembly of Au-loaded $\mathrm{SnO}_{2}$ hollow multilayered nanosheets for high-performance CO detection. Sens. Actuators B Chem. 2016, 227, 362-372. [CrossRef]

32. Zhang, S.; Song, P.; Yan, H.; Wang, Q. Self-assembled hierarchical Au-loaded $\operatorname{In}_{2} \mathrm{O}_{3}$ hollow microspheres with superior ethanol sensing properties. Sens. Actuators B Chem 2016, 231, 245-255. [CrossRef]

33. Zhang, K.; Yang, X.; Wang, Y.; Bing, Y.; Qiao, L.; Liang, Z.; Yu, S.; Zeng, Y.; Zheng, W. Pd-loaded $\mathrm{SnO}_{2}$ ultrathin nanorod-assembled hollow microspheres with the significant improvement for toluene detection. Sens. Actuators B Chem. 2017, 243, 465-474. [CrossRef]

34. Shao, F.; Hoffmann, M.W.G.; Prades, J.D.; Zamani, R.; Arbiol, J.; Morante, J.R.; Varechkina, E.; Rumyantseva, M.; Gaskov, A.; Giebelhaus, I.; et al. Heterostructured p-CuO (nanoparticle) $/ \mathrm{n}-\mathrm{SnO}_{2}$ (nanowire) devices for selective $\mathrm{H}_{2} \mathrm{~S}$ detection. Sens. Actuators B Chem. 2013, 181, 130-135. [CrossRef]

35. Kim, J.H.; Katoch, A.; Kim, S.S. Optimum shell thickness and underlying sensing mechanism in $p-n \mathrm{CuO}-\mathrm{ZnO}$ core-shell nanowires. Sens. Actuators B Chem. 2016, 222, 249-256. [CrossRef]

36. Tan, W.; Ruan, X.; Yu, Q.; Yu, Z.; Huang, X. Fabrication of a $\mathrm{SnO}_{2}$-based acetone gas sensor enhanced by molecular imprinting. Sensors 2014, 15, 352-364. [CrossRef] [PubMed]

37. Zhang, R.; Pang, W.; Feng, Z.H.; Chen, X.J.; Chen, Y.; Zhang, Q.; Zhang, H.; Sun, C.L.; Yang, J.J.; Zhang, D.H. Enabling selectivity and fast recovery of $\mathrm{ZnO}$ nanowire gas sensors through resistive switching. Sens. Actuators B Chem. 2017, 238, 357-363. [CrossRef]

38. Yin, M.L.; Yu, L.M.; Liu, S.Z. Synthesis of thickness-controlled cuboid $\mathrm{WO}_{3}$ nanosheets and their exposed facets-dependent acetone sensing properties. J. Alloys Compd. 2017, 696, 490-497. [CrossRef] 
39. Li, F.R.; Jian, J.K.; Wu, R.; Li, J.; Sun, Y.F. Synthesis, electrochemical and gas sensing properties of $\operatorname{In}_{2} \mathrm{O}_{3}$ nanostructures with different morphologies. J. Alloys Compd. 2015, 645, 178-183. [CrossRef]

40. Tian, K.; Wang, X.X.; Li, H.Y.; Nadimicherla, R.; Guo, X. Lotus pollen derived 3-dimensional hierarchically porous $\mathrm{NiO}$ microspheres for $\mathrm{NO}_{2}$ gas sensing. Sens. Actuators B Chem. 2016, 227, 554-560. [CrossRef]

41. Peng, X.Y.; Wang, Z.M.; Huang, P.; Chen, X.; Fu, X.Z.; Dai, W.X. Comparative Study of Two Different TiO 2 Film Sensors on Response to $\mathrm{H}_{2}$ under UV Light and Room Temperature. Sensors 2016, 16, 1249. [CrossRef] [PubMed]

42. Gleiter, H. Nanostructured materials: Basic concepts and microstructure. Acta Mater. 2000, 48, 1-29. [CrossRef]

43. Pokropivny, V.V.; Skorokhod, V.V. Classification of nanostructures by dimensionality and concept of surface forms engineering in nanomaterial science. Mater. Sci. Eng. C 2007, 27, 990-993. [CrossRef]

44. Gupta, A.; Sakthivel, T.; Seal, S. Recent development in 2D materials beyond graphene. Prog. Mater Sci. 2015, 73, 44-126. [CrossRef]

45. Akamatsu, T.; Itoh, T.; Izu, N.; Shin, W. NO and $\mathrm{NO}_{2}$ sensing properties of $\mathrm{WO}_{3}$ and $\mathrm{Co}_{3} \mathrm{O}_{4}$ based gas sensors. Sensors 2013, 13, 12467-12481. [CrossRef] [PubMed]

46. Bhardwaj, S.K.; Bhardwaj, N.; Kukkar, M.; Sharma, A.L.; Kim, K.H.; Deep, A. Formation of High-Purity Indium Oxide Nanoparticles and Their Application to Sensitive Detection of Ammonia. Sensors 2015, 15, 31930-31938. [CrossRef] [PubMed]

47. Zhang, W.L.; Yang, B.; Liu, J.Q.; Chen, X.; Wang, X.L.; Yang, C.S. Highly sensitive and low operating temperature $\mathrm{SnO}_{2}$ gas sensor doped by $\mathrm{Cu}$ and $\mathrm{Zn}$ two elements. Sens. Actuators B Chem. 2017, 243, 982-989. [CrossRef]

48. Wang, Q.J.; Liu, F.M.; Lin, J.; Lu, G.Y. Gas-sensing properties of In-Sn oxides composites synthesized by hydrothermal method. Sens. Actuators B Chem. 2016, 234, 130-136. [CrossRef]

49. Gao, H.T.; Jia, H.; Bierer, B.; Wöllenstein, J.; Lu, Y.; Palzer, S. Scalable gas sensors fabrication to integrate metal oxide nanoparticles with well-defined shape and size. Sens. Actuators B Chem. 2017, 249, 639-646. [CrossRef]

50. Wang, L.L.; Zhang, R.; Zhou, T.T.; Lou, Z.; Deng, J.N.; Zhang, T. Concave $\mathrm{Cu}_{2} \mathrm{O}$ octahedral nanoparticles as an advanced sensing material for benzene $\left(\mathrm{C}_{6} \mathrm{H}_{6}\right)$ and nitrogen dioxide $\left(\mathrm{NO}_{2}\right)$ detection. Sens. Actuators B Chem. 2016, 223, 311-317. [CrossRef]

51. Yu, H.X.; Song, Z.L.; Liu, Q.; Ji, X.; Liu, J.Q.; Xu, S.M.; Kan, H.; Zhang, B.H.; Liu, J.Y.; Jiang, J.J.; et al. Colloidal synthesis of tungsten oxide quantum dots for sensitive and selective $\mathrm{H}_{2} \mathrm{~S}$ gas detection. Sens. Actuators B Chem. 2017, 248, 1029-1036. [CrossRef]

52. Xiao, B.X.; Wang, F.; Zhai, C.B.; Wang, P.; Xiao, C.H.; Zhang, M.Z. Facile synthesis of $\operatorname{In}_{2} \mathrm{O}_{3}$ nanoparticles for sensing properties at low detection temperature. Sens. Actuators B Chem. 2016, 235, 251-257. [CrossRef]

53. Xu, C.N.; Tamaki, J.; Miura, N.; Yamazoe, N. Grain-size effects on gas sensitivity of porous $\mathrm{SnO}_{2}$-based elements. Sens. Actuators B Chem. 1991, 3, 147-155. [CrossRef]

54. Liang, S.; Li, J.P.; Wang, F.; Qin, J.L.; Lai, X.Y.; Jiang, X.M. Highly sensitive acetone gas sensor based on ultrafine $\alpha-\mathrm{Fe}_{2} \mathrm{O}_{3}$ nanoparticles. Sens. Actuators B Chem. 2017, 238, 923-927. [CrossRef]

55. Devan, R.S.; Patil, R.A.; Lin, J.H.; Ma, Y.R. One-Dimensional Metal-Oxide Nanostructures: Recent Developments in Synthesis, Characterization, and Applications. Adv. Funct. Mater. 2012, 22, 3326-3370. [CrossRef]

56. Qurashi, A.; Yamazaki, T.; El-Maghraby, E.M.; Kikuta, T. Fabrication and gas sensing properties of $\operatorname{In}_{2} \mathrm{O}_{3}$ nanopushpins. Appl. Phys. Lett. 2009, 95, 153109. [CrossRef]

57. Kong, X.H.; Li, Y.D. High sensitivity of $\mathrm{CuO}$ modified $\mathrm{SnO}_{2}$ nanoribbons to $\mathrm{H}_{2} \mathrm{~S}$ at room temperature. Sens. Actuators B Chem. 2005, 105, 449-453. [CrossRef]

58. Arafat, M.M.; Dinan, B.; Akbar, S.A.; Haseeb, A.S. Gas sensors based on one dimensional nanostructured metal-oxides: A review. Sensors 2012, 12, 7207-7258. [CrossRef] [PubMed]

59. Ying, Z.; Wan, Q.; Song, Z.T.; Feng, S.L. $\mathrm{SnO}_{2}$ nanowhiskers and their ethanol sensing characteristics. Nanotechnology 2004, 15, 1682-1684. [CrossRef]

60. Hu, P.Q.; Du, G.J.; Zhou, W.J.; Cui, J.J.; Lin, J.J.; Liu, H.; Liu, D.; Wang, J.Y.; Chen, S.W. Enhancement of ethanol vapor sensing of $\mathrm{TiO}_{2}$ nanobelts by surface engineering. ACS Appl. Mater. Interfaces 2010, 2, 3263-3269. [CrossRef] [PubMed] 
61. Zhao, Z.H.; Tian, J.; Sang, Y.H.; Cabot, A.; Liu, H. Structure, synthesis, and applications of TiO 2 nanobelts. Adv. Mater. 2015, 27, 2557-2582. [CrossRef] [PubMed]

62. Fang, F.; Bai, L.; Song, D.S.; Yang, H.P.; Sun, X.M.; Sun, H.Y.; Zhu, J. Ag-Modified $\mathrm{In}_{2} \mathrm{O}_{3} /$ ZnO Nanobundles with High Formaldehyde Gas-Sensing Performance. Sensors 2015, 15, 20086-20096. [CrossRef] [PubMed]

63. Chen, S.F.; Aldalbahi, A.; Feng, P.X. Nanostructured Tungsten Oxide Composite for High-Performance Gas Sensors. Sensors 2015, 15, 27035-27046. [CrossRef] [PubMed]

64. Woo, H.S.; Na, C.W.; Lee, J.H. Design of Highly Selective Gas Sensors via Physicochemical Modification of Oxide Nanowires: Overview. Sensors 2016, 16, 1531. [CrossRef] [PubMed]

65. Kim, J.H.; Abideen, Z.U.; Zheng, Y.; Kim, S.S. Improvement of Toluene-Sensing Performance of $\mathrm{SnO}_{2}$ Nanofibers by Pt Functionalization. Sensors 2016, 16, 1857. [CrossRef] [PubMed]

66. Yu, J.; Cheung, K.W.; Yan, W.H.A.; Li, Y.X.B.; Ho, D. High-sensitivity low-power tungsten doped niobium oxide nanorods sensor for nitrogen dioxide air pollution monitoring. Sens. Actuators B Chem. 2017, 238, 204-213. [CrossRef]

67. Zhao, C.H.; Bai, J.L.; Huang, B.Y.; Wang, Y.L.; Zhou, J.Y.; Xie, E.Q. Grain refining effect of calcium dopants on gas-sensing properties of electrospun alpha- $\mathrm{Fe}_{2} \mathrm{O}_{3}$ nanotubes. Sens. Actuators B Chem. 2016, 231, 552-560. [CrossRef]

68. Lupan, O.; Postica, V.; Ababii, N.; Hoppe, M.; Cretu, V.; Tiginyanu, I.; Sontea, V.; Pauporté, T.; Viana, B.; Adelung, R. Influence of $\mathrm{CuO}$ nanostructures morphology on hydrogen gas sensing performances. Microelectron. Eng. 2016, 164, 63-70. [CrossRef]

69. Sun, J.B.; Sun, P.; Zhang, D.L.; Xu, J.; Liang, X.S.; Liu, F.M.; Lu, G.Y. Growth of $\mathrm{SnO}_{2}$ nanowire arrays by ultrasonic spray pyrolysis and their gas sensing performance. RSC Adv. 2014, 4, 43429-43435. [CrossRef]

70. Nakla, W.; Wisitsora-at, A.; Tuantranont, A.; Singjai, P.; Phanichphant, S.; Liewhiran, C. $\mathrm{H}_{2} \mathrm{~S}$ sensor based on $\mathrm{SnO}_{2}$ nanostructured film prepared by high current heating. Sens. Actuators B Chem. 2014, 203, 565-578. [CrossRef]

71. Wang, H.R.; Sun, Q.; Yao, Y.Q.; Li, Y.X.; Wang, J.X.; Chen, L. A micro sensor based on $\mathrm{TiO}_{2}$ nanorod arrays for the detection of oxygen at room temperature. Ceram. Int. 2016, 42, 8565-8571. [CrossRef]

72. Oros, C.; Horprathum, M.; Wisitsoraat, A.; Srichaiyaperk, T.; Samransuksamer, B.; Limwichean, S.; Eiamchai, P.; Phokharatkul, D.; Nuntawong, N.; Chananonnawathorn, C.; et al. Ultra-sensitive $\mathrm{NO}_{2}$ sensor based on vertically aligned $\mathrm{SnO}_{2}$ nanorods deposited by DC reactive magnetron sputtering with glancing angle deposition technique. Sens. Actuators B Chem. 2016, 223, 936-945. [CrossRef]

73. Tshabalala, Z.P.; Shingange, K.; Dhonge, B.P.; Ntwaeaborwa, O.M.; Mhlongo, G.H.; Motaung, D.E. Fabrication of ultra-high sensitive and selective $\mathrm{CH}_{4}$ room temperature gas sensing of $\mathrm{TiO}_{2}$ nanorods: Detailed study on the annealing temperature. Sens. Actuators B Chem. 2017, 238, 402-419. [CrossRef]

74. Cao, S.X.; Zhao, C.; Han, T.; Peng, L.L. Hydrothermal synthesis, characterization and gas sensing properties of the $\mathrm{WO}_{3}$ nanofibers. Mater. Lett. 2016, 169, 17-20. [CrossRef]

75. Acharyya, D.; Bhattacharyya, P. Alcohol sensing performance of $\mathrm{ZnO}$ hexagonal nanotubes at low temperatures: A qualitative understanding. Sens. Actuators B Chem. 2016, 228, 373-386. [CrossRef]

76. Kaur, M.; Kailasaganapathi, S.; Ramgir, N.; Datta, N.; Kumar, S.; Debnath, A.K.; Aswal, D.K.; Gupta, S.K. Gas dependent sensing mechanism in ZnO nanobelt sensor. Appl. Surf. Sci. 2017, 394, 258-266. [CrossRef]

77. Cai, Z.X.; Li, H.Y.; Yang, X.N.; Guo, X. NO sensing by single crystalline $\mathrm{WO}_{3}$ nanowires. Sens. Actuators $B$ Chem. 2015, 219, 346-353. [CrossRef]

78. Chen, Y.; Xu, P.; Xu, T.; Zheng, D.; Li, X. ZnO-nanowire size effect induced ultra-high sensing response to ppb-level $\mathrm{H}_{2}$ S. Sens. Actuators B Chem. 2017, 240, 264-272. [CrossRef]

79. Lupan, O.; Ursaki, V.V.; Chai, G.; Chow, L.; Emelchenko, G.A.; Tiginyanu, I.M.; Gruzintsev, A.N.; Redkin, A.N. Selective hydrogen gas nanosensor using individual $\mathrm{ZnO}$ nanowire with fast response at room temperature. Sens. Actuators B Chem. 2010, 144, 56-66. [CrossRef]

80. Qin, Y.X.; Xie, W.W.; Liu, Y.; Ye, Z.H. Thermal-oxidative growth of aligned $\mathrm{W}_{18} \mathrm{O}_{49}$ nanowire arrays for high performance gas sensor. Sens. Actuators B Chem. 2016, 223, 487-495. [CrossRef]

81. Wang, L.H.; Cao, J.; Qian, X.M.; Zhang, H.M. Facile synthesis and enhanced gas sensing properties of grain size-adjustable $\mathrm{In}_{2} \mathrm{O}_{3}$ micro/nanotubes. Mater. Lett. 2016, 171, 30-33. [CrossRef]

82. Gurlo, A. Nanosensors: Towards morphological control of gas sensing activity. $\mathrm{SnO}_{2}, \mathrm{In}_{2} \mathrm{O}_{3}, \mathrm{ZnO}$ and $\mathrm{WO}_{3}$ case studies. Nanoscale 2011, 3, 154-165. [CrossRef] [PubMed] 
83. Yang, S.; Liu, Y.L.; Chen, W.; Jin, W.; Zhou, J.; Zhang, H.; Zakharova, G.S. High sensitivity and good selectivity of ultralong $\mathrm{MoO}_{3}$ nanobelts for trimethylamine gas. Sens. Actuators B Chem. 2016, 226, 478-485. [CrossRef]

84. Khalil, A.; Kim, J.J.; Tuller, H.L.; Rutledge, G.C.; Hashaikeh, R. Gas sensing behavior of electrospun nickel oxide nanofibers: Effect of morphology and microstructure. Sens. Actuators B Chem. 2016, 227, 54-64. [CrossRef]

85. Yoon, J.W.; Kim, H.J.; Jeong, H.M.; Lee, J.H. Gas sensing characteristics of p-type $\mathrm{Cr}_{2} \mathrm{O}_{3}$ and $\mathrm{Co}_{3} \mathrm{O}_{4}$ nanofibers depending on inter-particle connectivity. Sens. Actuators B Chem. 2014, 202, 263-271. [CrossRef]

86. Narasimman, S.; Balakrishnan, L.; Meher, S.R.; Sivacoumar, R.; Alex, Z.C. Influence of surface functionalization on the gas sensing characteristics of $\mathrm{ZnO}$ nanorhombuses. J. Alloys Compd. 2017, 706, 186-197. [CrossRef]

87. Dou, Y.H.; Xu, J.T.; Ruan, B.Y.; Liu, Q.N.; Pan, Y.D.; Sun, Z.Q.; Dou, S.X. Atomic Layer-by-Layer $\mathrm{Co}_{3} \mathrm{O}_{4} /$ Graphene Composite for High Performance Lithium-Ion Batteries. Adv. Energy Mater. 2016, 6, 1501835. [CrossRef]

88. Boota, M.; Anasori, B.; Voigt, C.; Zhao, M.Q.; Barsoum, M.W.; Gogotsi, Y. Pseudocapacitive Electrodes Produced by Oxidant-Free Polymerization of Pyrrole between the Layers of 2D Titanium Carbide (MXene). Adv. Mater. 2016, 28, 1517-1522. [CrossRef] [PubMed]

89. Miao, H.; Zhang, G.W.; Hu, X.Y.; Mu, J.L.; Han, T.X.; Fan, J.; Zhu, C.J.; Song, L.X.; Bai, J.T.; Hou, X. A novel strategy to prepare $2 \mathrm{D} \mathrm{g}-\mathrm{C}_{3} \mathrm{~N}_{4}$ nanosheets and their photoelectrochemical properties. J. Alloys Compd. 2017, 690, 669-676. [CrossRef]

90. Nijamudheen, A.; Akimov, A.V. Excited-State Dynamics in Two-Dimensional Heterostructures: $\mathrm{SiR} / \mathrm{TiO} 2$ and $\mathrm{GeR} / \mathrm{TiO}_{2}(\mathrm{R}=\mathrm{H}, \mathrm{Me})$ as Promising Photocatalysts. J. Phys. Chem. C 2017, 121, 6520-6532. [CrossRef]

91. Ji, F.X.; Ren, X.P.; Zheng, X.Y.; Liu, Y.C.; Pang, L.Q.; Jiang, J.X.; Liu, S.Z. 2D-MoO3 nanosheets for superior gas sensors. Nanoscale 2016, 8, 8696-8703. [CrossRef] [PubMed]

92. Xu, J.Q.; Xue, Z.G.; Qin, N.; Cheng, Z.X.; Xiang, Q. The crystal facet-dependent gas sensing properties of ZnO nanosheets: Experimental and computational study. Sens. Actuators B Chem. 2017, 242, 148-157. [CrossRef]

93. Liu, C.; Lu, H.B.; Zhang, J.N.; Yang, Z.B.; Zhu, G.Q.; Yin, F.; Gao, J.Z.; Chen, C.J.; Xin, X. Abnormal p-type sensing response of $\mathrm{TiO}_{2}$ nanosheets with exposed \{001\} facets. J. Alloys Compd. 2017, 705, 112-117. [CrossRef]

94. Godbole, R.; Godbole, V.P.; Bhagwat, S. Surface morphology dependent tungsten oxide thin films as toxic gas sensor. Mater. Sci. Semicond. Process. 2017, 63, 212-219. [CrossRef]

95. Cho, Y.H.; Ko, Y.N.; Kang, Y.C.; Kim, I.-D.; Lee, J.-H. Ultraselective and ultrasensitive detection of trimethylamine using $\mathrm{MoO}_{3}$ nanoplates prepared by ultrasonic spray pyrolysis. Sens. Actuators B Chem. 2014, 195, 189-196. [CrossRef]

96. Rouquerol, J.; Avnir, D.; Fairbridge, C.W.; Everett, D.H.; Haynes, J.H.; Pernicone, N.; Ramsay, J.D.F.; Sing, K.S.W.; Unger, K.K. Recommendations for the characterization of porous solids. Pure Appl. Chem. 1994, 66, 1739-1758. [CrossRef]

97. Wang, X.; Su, J.; Chen, H.; Li, G.D.; Shi, Z.F.; Zou, H.F.; Zou, X.X. Ultrathin $\mathrm{In}_{2} \mathrm{O}_{3}$ Nanosheets with Uniform Mesopores for Highly Sensitive Nitric Oxide Detection. ACS Appl. Mater. Interfaces 2017, 9, 16335-16342. [CrossRef] [PubMed]

98. Li, Z.J.; Lin, Z.J.; Wang, N.N.; Wang, J.Q.; Liu, W.; Sun, K.; Fu, Y.Q.; Wang, Z.G. High precision $\mathrm{NH}_{3}$ sensing using network nano-sheet $\mathrm{Co}_{3} \mathrm{O}_{4}$ arrays based sensor at room temperature. Sens. Actuators B Chem. 2016, 235, 222-231. [CrossRef]

99. Escalante, G.; Juárez, H.; Fernández, P. Characterization and sensing properties of ZnO film prepared by single source chemical vapor deposition. Adv. Powder Technol. 2017, 28, 23-29. [CrossRef]

100. Zhang, Z.Y.; Wen, Z.; Ye, Z.Z.; Zhu, L.P. Gas sensors based on ultrathin porous $\mathrm{Co}_{3} \mathrm{O}_{4}$ nanosheets to detect acetone at low temperature. RSC Adv. 2015, 5, 59976-59982. [CrossRef]

101. Xiao, C.H.; Yang, T.Y.; Chuai, M.Y.; Xiao, B.X.; Zhang, M.Z. Synthesis of ZnO nanosheet arrays with exposed (100) facets for gas sensing applications. Phys. Chem. Chem. Phys. 2016, 18, 325-330. [CrossRef] [PubMed]

102. Guo, W.; Feng, Q.Q.; Tao, Y.F.; Zheng, L.J.; Han, Z.Y.; Ma, J.M. Systematic investigation on the gas-sensing performance of $\mathrm{TiO}_{2}$ nanoplate sensors for enhanced detection on toxic gases. Mater. Res. Bull. 2016, 73, 302-307. [CrossRef]

103. Shendage, S.S.; Patil, V.L.; Vanalakar, S.A.; Patil, S.P.; Harale, N.S.; Bhosale, J.L.; Kim, J.H.; Patil, P.S. Sensitive and selective $\mathrm{NO}_{2}$ gas sensor based on $\mathrm{WO}_{3}$ nanoplates. Sens. Actuators B Chem. 2017, 240, 426-433. [CrossRef] 
104. Qin, H.Y.; Cao, Y.L.; Xie, J.; Xu, H.; Jia, D.Z. Solid-state chemical synthesis and xylene-sensing properties of $\alpha-\mathrm{MoO}_{3}$ arrays assembled by nanoplates. Sens. Actuators B Chem. 2017, 242, 769-776. [CrossRef]

105. Maity, A.; Majumder, S.B. $\mathrm{NO}_{2}$ sensing and selectivity characteristics of tungsten oxide thin films. Sens. Actuators B Chem. 2015, 206, 423-429. [CrossRef]

106. Teimoori, F.; Khojier, K.; Dehnavi, N.Z. Investigation of sensitivity and selectivity of ZnO thin film to volatile organic compounds. J. Theor. Appl. Phys. 2017, 11, 157-163. [CrossRef]

107. Karthikeyan, P.S.; Dhivya, P.; Deepak Raj, P.; Sridharan, $\mathrm{M} . \mathrm{V}_{2} \mathrm{O}_{5}$ thin film for 2-Propanol vapor sensing. Mater. Today Proc. 2016, 3, 1510-1516. [CrossRef]

108. Yu, L.M.; Guo, F.; Liu, S.; Yang, B.; Jiang, Y.X.; Qi, L.J.; Fan, X.H. Both oxygen vacancies defects and porosity facilitated $\mathrm{NO}_{2}$ gas sensing response in $2 \mathrm{D} \mathrm{ZnO}$ nanowalls at room temperature. J. Alloys Compd. 2016, 682, 352-356. [CrossRef]

109. Wu, B.F.; Wang, L.L.; Wu, H.Y.; Kan, K.; Zhang, G.; Xie, Y.; Tian, Y.; Li, L.; Shi, K.Y. Templated synthesis of 3D hierarchical porous $\mathrm{Co}_{3} \mathrm{O}_{4}$ materials and their $\mathrm{NH}_{3}$ sensor at room temperature. Microporous Mesoporous Mater. 2016, 225, 154-163. [CrossRef]

110. Wang, S.R.; Yang, J.D.; Zhang, H.X.; Wang, Y.S.; Gao, X.L.; Wang, L.W.; Zhu, Z.Y. One-pot synthesis of $3 \mathrm{D}$ hierarchical $\mathrm{SnO}_{2}$ nanostructures and their application for gas sensor. Sens. Actuators B Chem. 2015, 207, 83-89. [CrossRef]

111. Li, T.M.; Zeng, W. New insight into the gas sensing performance of $\mathrm{SnO}_{2}$ Nanorod-assembled urchins based on their assembly density. Ceram. Int. 2017, 43, 728-735. [CrossRef]

112. Xu, K.; Yang, L.; Zou, J.P.; Yang, Y.; Li, Q.L.; Qu, Y.H.; Ye, J.R.; Yuan, C.L. Fabrication of novel flower-like $\mathrm{Co}_{3} \mathrm{O}_{4}$ structures assembled by single-crystalline porous nanosheets for enhanced xylene sensing properties. J. Alloys Compd. 2017, 706, 116-125. [CrossRef]

113. Diao, K.D.; Zhou, M.J.; Zhang, J.C.; Tang, Y.J.; Wang, S.X.; Cui, X.D. High response to $\mathrm{H}_{2} \mathrm{~S}$ gas with facile synthesized hierarchical ZnO microstructures. Sens. Actuators B Chem. 2015, 219, 30-37. [CrossRef]

114. Liu, J.; Huang, H.W.; Zhao, H.; Yan, X.T.; Wu, S.J.; Li, Y.; Wu, M.; Chen, L.H.; Yang, X.Y.; Su, B.L. Enhanced Gas Sensitivity and Selectivity on Aperture-Controllable 3D Interconnected Macro-Mesoporous ZnO Nanostructures. ACS Appl. Mater. Interfaces 2016, 8, 8583-8590. [CrossRef] [PubMed]

115. Xu, X.M.; Zhang, H.J.; Hu, X.L.; Sun, P.; Zhu, Y.S.; He, C.Z.; Hou, S.J.; Sun, Y.F.; Lu, G.Y. Hierarchical nanorod-flowers indium oxide microspheres and their gas sensing properties. Sens. Actuators $B$ Chem. 2016, 227, 547-553. [CrossRef]

116. Li, Y.X.; Chen, N.; Deng, D.Y.; Xing, X.X.; Xiao, X.C.; Wang, Y.D. Formaldehyde detection: $\mathrm{SnO}_{2}$ microspheres for formaldehyde gas sensor with high sensitivity, fast response/recovery and good selectivity. Sens. Actuators B Chem. 2017, 238, 264-273. [CrossRef]

117. Sui, L.L.; Xu, Y.M.; Zhang, X.F.; Cheng, X.L.; Gao, S.; Zhao, H.; Cai, Z.; Huo, L.H. Construction of three-dimensional flower-like $\alpha-\mathrm{MoO}_{3}$ with hierarchical structure for highly selective triethylamine sensor. Sens. Actuators B Chem. 2015, 208, 406-414. [CrossRef]

118. Jiang, X.H.; Ma, S.Y.; Sun, A.M.; Zhang, Z.M.; Jin, W.X.; Wang, T.T.; Li, W.Q.; Xu, X.L.; Luo, J.; Cheng, L.; et al. Hydrothermal self-assembly of novel porous flower-like $\mathrm{SnO}_{2}$ architecture and its application in ethanol sensor. Appl. Surf. Sci. 2015, 355, 1192-1200. [CrossRef]

119. Miao, R.Y.; Zeng, W. Hydrothermal synthesis of flake-flower NiO architectures: Structure, growth and gas-sensing properties. Mater. Lett. 2016, 171, 200-203. [CrossRef]

120. Song, L.M.; Li, Y.; Li, S.C.; Liu, L.; Wang, L.Y.; Guo, X.X.; Lian, H.W. Porous ZnO microflowers with ultrahigh sensitive and selective properties to ethanol. J. Mater. Sci. Mater. Electron. 2016, 28, 652-656. [CrossRef]

121. Jin, W.X.; Ma, S.Y.; Tie, Z.Z.; Li, W.Q.; Luo, J.; Cheng, L.; Xu, X.L.; Wang, T.T.; Jiang, X.H.; Mao, Y.Z. Synthesis of hierarchical $\mathrm{SnO}_{2}$ nanoflowers with enhanced acetic acid gas sensing properties. Appl. Surf. Sci. 2015, 353, 71-78. [CrossRef]

122. Wang, C.; Li, X.; Feng, C.H.; Sun, Y.F.; Lu, G.Y. Nanosheets assembled hierarchical flower-like $\mathrm{WO}_{3}$ nanostructures: Synthesis, characterization, and their gas sensing properties. Sens. Actuators B Chem. 2015, 210, 75-81. [CrossRef]

123. Cao, S.X.; Chen, H.; Han, T.; Zhao, C.; Peng, L.L. Rose-like $\mathrm{Cu}_{2} \mathrm{O}$ nanoflowers via hydrothermal synthesis and their gas sensing properties. Mater. Lett. 2016, 180, 135-139. [CrossRef]

124. Qiang, Z.; Ma, S.Y.; Jiao, H.Y.; Jin, W.X.; Wang, T.T.; Jiang, X.H.; Zhang, Z.Y. Solvothermal synthesis of 3D leaf-like $\alpha-\mathrm{Fe}_{2} \mathrm{O}_{3}$ and its gas-sensing properties research. Mater. Lett. 2016, 181, 29-33. [CrossRef] 
125. Cao, S.X.; Chen, H. Nanorods assembled hierarchical urchin-like $\mathrm{WO}_{3}$ nanostructures: Hydrothermal synthesis, characterization, and their gas sensing properties. J. Alloys Compd. 2017, 702, 644-648. [CrossRef]

126. Lu, Y.; Ma, Y.H.; Ma, S.Y.; Jin, W.X.; Yan, S.H.; Xu, X.L.; Jiang, X.H.; Wang, T.T.; Yang, H.M.; Chen, H.; et al. Synthesis of cactus-like $\mathrm{NiO}$ nanostructure and their gas-sensing properties. Mater. Lett. 2016, 164, 48-51. [CrossRef]

127. Wang, S.M.; Cao, J.; Cui, W.; Li, X.F.; Li, D.J. Facile synthesis and excellent formaldehyde gas sensing properties of novel spindle-like $\mathrm{In}_{2} \mathrm{O}_{3}$ porous polyhedra. Sens. Actuators B Chem. 2016, 237, 944-952. [CrossRef]

128. Sun, P.; Wang, C.; Liu, J.Y.; Zhou, X.; Li, X.W.; Hu, X.L.; Lu, G.Y. Hierarchical Assembly of alpha-Fe $\mathrm{F}_{2} \mathrm{O}_{3}$ Nanosheets on $\mathrm{SnO}_{2}$ Hollow Nanospheres with Enhanced Ethanol Sensing Properties. ACS Appl. Mater. Interfaces 2015, 7, 19119-19125. [CrossRef] [PubMed]

129. Qi, J.; Lai, X.Y.; Wang, J.Y.; Tang, H.J.; Ren, H.; Yang, Y.; Jin, Q.; Zhang, L.J.; Yu, R.B.; Ma, G.H.; et al. Multi-shelled hollow micro-/nanostructures. Chem. Soc. Rev. 2015, 44, 6749-6773. [CrossRef] [PubMed]

130. Chen, Y.; Li, X.G.; Li, X.X.; Wang, J.; Tang, Z.A. UV activated hollow ZnO microspheres for selective ethanol sensors at low temperatures. Sens. Actuators B Chem. 2016, 232, 158-164. [CrossRef]

131. Shen, J.Y.; Zhang, L.; Ren, J.; Wang, J.C.; Yao, H.C.; Li, Z.J. Highly enhanced acetone sensing performance of porous C-doped $\mathrm{WO}_{3}$ hollow spheres by carbon spheres as templates. Sens. Actuators B Chem. 2017, 239, 597-607. [CrossRef]

132. Li, W.H.; Wu, X.F.; Han, N.; Chen, J.Y.; Qian, X.H.; Deng, Y.Z.; Tang, W.X.; Chen, Y.F. MOF-derived hierarchical hollow $\mathrm{ZnO}$ nanocages with enhanced low-concentration VOCs gas-sensing performance. Sens. Actuators B Chem. 2016, 225, 158-166. [CrossRef]

133. Zhou, T.T.; Zhang, T.; Zhang, R.; Deng, J.N.; Lou, Z.; Lu, G.Y.; Wang, L.L. Highly sensitive sensing platform based on $\mathrm{ZnSnO}_{3}$ hollow cubes for detection of ethanol. Appl. Surf. Sci. 2017, 400, 262-268. [CrossRef]

134. Liu, J.Y.; Dai, M.J.; Wang, T.S.; Sun, P.; Liang, X.S.; Lu, G.Y.; Shimanoe, K.; Yamazoe, N. Enhanced Gas Sensing Properties of $\mathrm{SnO}_{2}$ Hollow Spheres Decorated with $\mathrm{CeO}_{2}$ Nanoparticles Heterostructure Composite Materials. ACS Appl. Mater. Interfaces 2016, 8, 6669-6677. [CrossRef] [PubMed]

135. Yang, H.M.; Ma, S.Y.; Jiao, H.Y.; Chen, Q.; Lu, Y.; Jin, W.X.; Li, W.Q.; Wang, T.T.; Jiang, X.H.; Qiang, Z.; et al. Synthesis of $\mathrm{Zn}_{2} \mathrm{SnO}_{4}$ hollow spheres by a template route for high-performance acetone gas sensor. Sens. Actuators B Chem. 2017, 245, 493-506. [CrossRef]

136. Sun, H.M.; Wang, L.M.; Chu, D.Q.; Ma, Z.C.; Wang, A.X. Facile fabrication of multishelled $\mathrm{Cr}_{2} \mathrm{O}_{3}$ hollow microspheres with enhanced gas sensitivity. Mater. Lett. 2015, 140, 158-161. [CrossRef]

137. Zhou, X.; Li, X.W.; Sun, H.B.; Sun, P.; Liang, X.S.; Liu, F.M.; Hu, X.L.; Lu, G.Y. Nanosheet-assembled $\mathrm{ZnFe}_{2} \mathrm{O}_{4}$ hollow microspheres for high-sensitive acetone sensor. ACS Appl. Mater. Interfaces 2015, 7, 15414-15421. [CrossRef] [PubMed]

138. Zhang, W.; Cheng, X.L.; Zhang, X.F.; Xu, Y.M.; Gao, S.; Zhao, H.; Huo, L.H. High selectivity to ppb-level $\mathrm{HCHO}$ sensor based on mesoporous tubular $\mathrm{SnO}_{2}$ at low temperature. Sens. Actuators B Chem. 2017, 247, 664-672. [CrossRef]

139. Yang, Y.; Liang, Y.; Wang, G.Z.; Liu, L.L.; Yuan, C.L.; Yu, T.; Li, Q.L.; Zeng, F.Y.; Gu, G. Enhanced Gas-Sensing Properties of the Hierarchical $\mathrm{TiO}_{2}$ Hollow Microspheres with Exposed High-Energy $\{001\}$ Crystal Facets. ACS Appl. Mater. Interfaces 2015, 7, 24902-24908. [CrossRef] [PubMed]

140. Yang, H.M.; Ma, S.Y.; Yang, G.J.; Jin, W.X.; Wang, T.T.; Jiang, X.H.; Li, W.Q. High sensitive and low concentration detection of methanol by a gas sensor based on one-step synthesis $\alpha-\mathrm{Fe}_{2} \mathrm{O}_{3}$ hollow spheres. Mater. Lett. 2016, 169, 73-76. [CrossRef]

141. Li, J.W.; Liu, X.; Cui, J.S.; Sun, J.B. Hydrothermal synthesis of self-assembled hierarchical tungsten oxides hollow spheres and their gas sensing properties. ACS Appl. Mater. Interfaces 2015, 7, 10108-10114. [CrossRef] [PubMed]

142. Wang, C.; Feng, C.H.; Wang, M.; Li, X.; Cheng, P.F.; Zhang, H.; Sun, Y.F.; Sun, P.; Lu, G.Y. One-pot synthesis of hierarchical $\mathrm{WO}_{3}$ hollow nanospheres and their gas sensing properties. RSC Adv. 2015, 5, 29698-29703. [CrossRef]

143. Yang, J.D.; Wang, S.R.; Dong, R.; Zhang, L.P.; Zhu, Z.Y.; Gao, X.L. One-pot synthesis of $\mathrm{SnO}_{2}$ hollow microspheres and their formaldehyde sensor application. Mater. Lett. 2016, 184, 9-12. [CrossRef] 
144. Jia, X.H.; Tian, M.G.; Dai, R.R.; Lian, D.D.; Han, S.; Wu, X.Y.; Song, H.J. One-pot template-free synthesis and highly ethanol sensing properties of $\mathrm{ZnSnO}_{3}$ hollow microspheres. Sens. Actuators B Chem. 2017, 240, 376-385. [CrossRef]

145. Qiang, Z.; Ma, S.Y.; Jiao, H.Y.; Wang, T.T.; Jiang, X.H.; Jin, W.X.; Yang, H.M.; Chen, H. Highly sensitive and selective ethanol sensors using porous $\mathrm{SnO}_{2}$ hollow spheres. Ceram. Int. 2016, 42, 18983-18990. [CrossRef]

146. Wang, T.T.; Ma, S.Y.; Cheng, L.; Jiang, X.H.; Zhang, M.; Li, W.Q.; Jin, W.X. Facile fabrication of multishelled $\mathrm{SnO}_{2}$ hollow microspheres for gas sensing application. Mater. Lett. 2016, 164, 56-59. [CrossRef]

147. Dong, C.J.; Xing, X.X.; Chen, N.; Liu, X.; Wang, Y.D. Biomorphic synthesis of hollow CuO fibers for low-ppm-level n-propanol detection via a facile solution combustion method. Sens. Actuators B Chem. 2016, 230, 1-8. [CrossRef]

148. Zeng, Y.; Wang, Y.Z.; Qiao, L.; Bing, Y.F.; Zou, B.; Zheng, W.T. Synthesis and the improved sensing properties of hierarchical $\mathrm{SnO}_{2}$ hollow nanosheets with mesoporous and multilayered interiors. Sens. Actuators B Chem. 2016, 222, 354-361. [CrossRef]

149. Wei, S.H.; Han, L.X.; Wang, M.Y.; Zhang, H.H.; Du, W.M.; Zhou, M.H. Hollow cauliflower-like $W_{3}$ nanostructures: Hydrothermal synthesis and their CO sensing properties. Mater. Lett. 2017, 186, 259-262. [CrossRef]

150. Jin, W.X.; Ma, S.Y.; Tie, Z.Z.; Xu, X.L.; Jiang, X.H.; Li, W.Q.; Wang, T.T.; Lu, Y.; Yan, S.H. Synthesis of monodisperse $\mathrm{ZnO}$ hollow six-sided pyramids and their high gas-sensing properties. Mater. Lett. 2015, 159, 102-105. [CrossRef]

151. Chen, Q.; Ma, S.Y.; Jiao, H.Y.; Zhang, G.H.; Chen, H.; Xu, X.L.; Yang, H.M.; Qiang, Z. Synthesis of novel $\mathrm{ZnSnO}_{3}$ hollow polyhedrons with open nanoholes: Enhanced acetone-sensing performance. Ceram. Int. 2017, 43, 1617-1621. [CrossRef]

152. Xu, W.; Li, J.W.; Sun, J.B. Fabrication of monodispersed hollow flower-like porous $\operatorname{In}_{2} \mathrm{O}_{3}$ nanostructures and their application as gas sensors. RSC Adv. 2015, 5, 81407-81414. [CrossRef]

153. Tan, J.F.; Dun, M.H.; Li, L.; Zhao, J.Y.; Tan, W.H.; Lin, Z.D.; Huang, X.T. Synthesis of hollow and hollowed-out $\mathrm{Co}_{3} \mathrm{O}_{4}$ microspheres assembled by porous ultrathin nanosheets for ethanol gas sensors: Responding and recovering in one second. Sens. Actuators B Chem. 2017, 249, 44-52. [CrossRef]

154. Zhang, J.; Song, P.; Li, J.; Yang, Z.X.; Wang, Q. Template-assisted synthesis of hierarchical $\mathrm{MoO}_{3}$ microboxes and their high gas-sensing performance. Sens. Actuators B Chem. 2017, 249, 458-466. [CrossRef]

155. Li, J.; Tang, P.G.; Zhang, J.J.; Feng, Y.J.; Luo, R.X.; Chen, A.F.; Li, D.Q. Facile Synthesis and Acetone Sensing Performance of Hierarchical $\mathrm{SnO}_{2}$ Hollow Microspheres with Controllable Size and Shell Thickness. Ind. Eng. Chem. Res. 2016, 55, 3588-3595. [CrossRef]

156. Katoch, A.; Abideen, Z.U.; Kim, J.H.; Kim, S.S. Influence of hollowness variation on the gas-sensing properties of ZnO hollow nanofibers. Sens. Actuators B Chem. 2016, 232, 698-704. [CrossRef]

157. Mirzaei, A.; Janghorban, K.; Hashemi, B.; Neri, G. Metal-core@metal oxide-shell nanomaterials for gas-sensing applications: A review. J. Nanopart. Res. 2015, 17, 371. [CrossRef]

158. Majhi, S.M.; Rai, P.; Yu, Y.T. Facile Approach to Synthesize Au@ZnO Core-Shell Nanoparticles and Their Application for Highly Sensitive and Selective Gas Sensors. ACS Appl. Mater. Interfaces 2015, 7, 9462-9468. [CrossRef] [PubMed]

159. Qu, F.D.; Jiang, H.F.; Yang, M.H. MOF-derived $\mathrm{Co}_{3} \mathrm{O}_{4} / \mathrm{NiCo}_{2} \mathrm{O}_{4}$ double-shelled nanocages with excellent gas sensing properties. Mater. Lett. 2017, 190, 75-78. [CrossRef]

160. Yu, Q.X.; Zhu, J.H.; Xu, Z.Y.; Huang, X.T. Facile synthesis of $\alpha-\mathrm{Fe}_{2} \mathrm{O}_{3} @ \mathrm{SnO}_{2}$ core-shell heterostructure nanotubes for high performance gas sensors. Sens. Actuators B Chem. 2015, 213, 27-34. [CrossRef]

161. Zhang, B.W.; Fu, W.Y.; Li, H.Y.; Fu, X.L.; Wang, Y.; Bala, H.; Sun, G.; Wang, X.D.; Wang, Y.; Cao, J.L.; et al. Actinomorphic $\mathrm{ZnO} / \mathrm{SnO}_{2}$ core-shell nanorods: Two-step synthesis and enhanced ethanol sensing propertied. Mater. Lett. 2015, 160, 227-230. [CrossRef]

162. Song, H.M.; Chon, B.S.; Jeon, S.H.; Rai, P.; Yu, Y.T.; Dutta, P.K. Synthesis of $\mathrm{Au} @ \mathrm{SnO}_{2}$ core-shell nanoparticles with controllable shell thickness and their CO sensing properties. Mater. Chem. Phys. 2015, 166, 87-94. [CrossRef]

163. Zhu, Z.; Chang, J.L.; Wu, R.J. Fast ozone detection by using a core-shell $\mathrm{Au} @ \mathrm{TiO}_{2}$ sensor at room temperature. Sens. Actuators B Chem. 2015, 214, 56-62. [CrossRef] 
164. Li, F.; Gao, X.; Wang, R.; Zhang, T.; Lu, G.Y.; Barsan, N. Design of Core-Shell Heterostructure Nanofibers with Different Work Function and Their Sensing Properties to Trimethylamine. ACS Appl. Mater. Interfaces 2016, 8, 19799-19806. [CrossRef] [PubMed]

165. Cao, J.; Wang, Z.Y.; Wang, R.; Liu, S.; Fei, T.; Wang, L.J.; Zhang, T. Synthesis of core-shell alpha-Fe ${ }_{2} \mathrm{O}_{3} @ \mathrm{NiO}$ nanofibers with hollow structures and their enhanced HCHO sensing properties. J. Mater. Chem. A 2015, 3, 5635-5641. [CrossRef]

166. Liu, Y.S.; Yang, P.; Li, J.; Matras-Postolek, K.; Yue, Y.L.; Huang, B.B. Formation of $\mathrm{SiO}_{2} @ S n \mathrm{O}_{2}$ core-shell nanofibers and their gas sensing properties. RSC Adv. 2016, 6, 13371-13376. [CrossRef]

167. Li, W.Q.; Ma, S.Y.; Li, Y.F.; Yang, G.J.; Mao, Y.Z.; Luo, J.; Gengzang, D.; Xu, X.L.; Yan, S.H. Enhanced ethanol sensing performance of hollow $\mathrm{ZnO}-\mathrm{SnO}_{2}$ core-shell nanofibers. Sens. Actuators B Chem. 2015, 211, 392-402. [CrossRef]

168. Qin, Y.X.; Zhang, X.J.; Wang, Y.Y.; Liu, Y. Remarkable improvement of $\mathrm{W}_{18} \mathrm{O}_{49} / \mathrm{TiO}_{2}$ heteronanowires in ambient temperature-responsive $\mathrm{NO}_{2}$-sensing abilities and its unexpected $n$ - $p$ transition phenomenon. Sens. Actuators B Chem. 2017, 240, 477-486. [CrossRef]

169. Wang, Y.F.; Qu, F.D.; Liu, J.; Wang, Y.; Zhou, J.R.; Ruan, S.P. Enhanced $\mathrm{H}_{2} \mathrm{~S}$ sensing characteristics of CuO-NiO core-shell microspheres sensors. Sens. Actuators B Chem. 2015, 209, 515-523. [CrossRef]

170. Wang, L.L.; Lou, Z.; Zhang, R.; Zhou, T.T.; Deng, J.N.; Zhang, T. Hybrid $\mathrm{Co}_{3} \mathrm{O}_{4} / \mathrm{SnO}_{2}$ Core-Shell Nanospheres as Real-Time Rapid-Response Sensors for Ammonia Gas. ACS Appl. Mater. Interfaces 2016, 8, 6539-6545. [CrossRef] [PubMed]

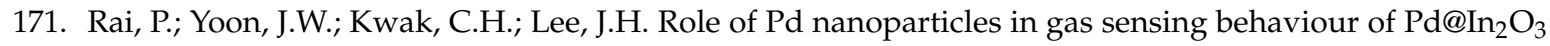
yolk-shell nanoreactors. J. Mater. Chem. A 2016, 4, 264-269. [CrossRef]

172. Gu, F.B.; Chen, H.H.; Han, D.M.; Wang, Z.H. Metal-organic framework derived Au@ZnO yolk-shell nanostructures and their highly sensitive detection of acetone. RSC Adv. 2016, 6, 29727-29733. [CrossRef]

173. Gao, X.M.; Li, C.Y.; Yin, Z.X.; Chen, Y.J. Synthesis and $\mathrm{H}_{2} \mathrm{~S}$ sensing performance of $\mathrm{MoO}_{3} / \mathrm{Fe}_{2}\left(\mathrm{MoO}_{4}\right)_{3}$ yolk/shell nanostructures. RSC Adv. 2015, 5, 37703-37709. [CrossRef]

174. Zhou, X.; Wang, B.Q.; Sun, H.B.; Wang, C.; Sun, P.; Li, X.W.; Hu, X.L.; Lu, G.Y. Template-free synthesis of hierarchical $\mathrm{ZnFe}_{2} \mathrm{O}_{4}$ yolk-shell microspheres for high-sensitivity acetone sensors. Nanoscale 2016, 8, 5446-5453. [CrossRef] [PubMed]

175. Wang, L.L.; Lou, Z.; Deng, J.N.; Zhang, R.; Zhang, T. Ethanol Gas Detection Using a Yolk-Shell (Core-Shell) alpha- $\mathrm{Fe}_{2} \mathrm{O}_{3}$ Nanospheres as Sensing Material. ACS Appl. Mater. Interfaces 2015, 7, 13098-13104. [CrossRef] [PubMed]

176. Kim, J.S.; Yoon, J.W.; Hong, Y.J.; Kang, Y.C.; Abdel-Hady, F.; Wazzan, A.A.; Lee, J.H. Highly sensitive and selective detection of ppb-level $\mathrm{NO}_{2}$ using multi-shelled $\mathrm{WO}_{3}$ yolk-shell spheres. Sens. Actuators B Chem. 2016, 229, 561-569. [CrossRef]

177. Bing, Y.F.; Liu, C.; Qiao, L.; Zeng, Y.; Yu, S.S.; Liang, Z.Z.; Liu, J.P.; Luo, J.Z.; Zheng, W.T. Multistep synthesis of non-spherical $\mathrm{SnO}_{2} @ \mathrm{SnO}_{2}$ yolk-shell cuboctahedra with nanoparticle-assembled porous structure for toluene detection. Sens. Actuators B Chem. 2016, 231, 365-375. [CrossRef]

178. Li, X.W.; Liu, J.Y.; Guo, H.; Zhou, X.; Wang, C.; Sun, P.; Hu, X.L.; Lu, G.Y. Au@In ${ }_{2} \mathrm{O}_{3}$ core-shell composites: A metal-semiconductor heterostructure for gas sensing applications. RSC Adv. 2015, 5, 545-551. [CrossRef]

179. Qu, F.D.; Jiang, H.F.; Yang, M.H. Designed formation through a metal organic framework route of $\mathrm{ZnO} / \mathrm{ZnCo}_{2} \mathrm{O}_{4}$ hollow core-shell nanocages with enhanced gas sensing properties. Nanoscale 2016, 8, 16349-16356. [CrossRef] [PubMed]

180. Dankeaw, A.; Poungchan, G.; Panapoy, M.; Ksapabutr, B. In-situ one-step method for fabricating three-dimensional grass-like carbon-doped $\mathrm{ZrO}_{2}$ films for room temperature alcohol and acetone sensors. Sens. Actuators B Chem. 2017, 242, 202-214. [CrossRef]

181. Vallejos, S.; Grácia, I.; Chmela, O.; Figueras, E.; Hubálek, J.; Cané, C. Chemoresistive micromachined gas sensors based on functionalized metal oxide nanowires: Performance and reliability. Sens. Actuators B Chem. 2016, 235, 525-534. [CrossRef]

182. Han, D.; Song, P.; Zhang, S.; Zhang, H.H.; Xu, Q.; Wang, Q. Enhanced methanol gas-sensing performance of Ce-doped $\mathrm{In}_{2} \mathrm{O}_{3}$ porous nanospheres prepared by hydrothermal method. Sens. Actuators B Chem. 2015, 216, 488-496. [CrossRef] 
183. NaderiNasrabadi, M.; Mortazavi, Y.; Khodadadi, A.A. Highly sensitive and selective $\mathrm{Gd}_{2} \mathrm{O}_{3}$-doped $\mathrm{SnO}_{2}$ ethanol sensors synthesized by a high temperature and pressure solvothermal method in a microreactor. Sens. Actuators B Chem. 2016, 230, 130-139. [CrossRef]

184. Wang, S.C.; Shaikh, M.O. A Room Temperature $\mathrm{H}_{2}$ Sensor Fabricated Using High Performance Pt-Loaded $\mathrm{SnO}_{2}$ Nanoparticles. Sensors 2015, 15, 14286-14297. [CrossRef] [PubMed]

185. Qiao, L.; Bing, Y.F.; Wang, Y.Z.; Yu, S.S.; Liang, Z.Z.; Zeng, Y. Enhanced toluene sensing performances of Pd-loaded $\mathrm{SnO}_{2}$ cubic nanocages with porous nanoparticle-assembled shells. Sens. Actuators B Chem. 2017, 241, 1121-1129. [CrossRef]

186. Wang, Y.L.; Liu, J.; Cui, X.B.; Gao, Y.; Ma, J.; Sun, Y.F.; Sun, P.; Liu, F.M.; Liang, X.S.; Zhang, T.; et al. NH $\mathrm{NH}_{3}$ gas sensing performance enhanced by Pt-loaded on mesoporous $\mathrm{WO}_{3}$. Sens. Actuators B Chem. 2017, 238, 473-481. [CrossRef]

187. Fan, F.Y.; Zhang, J.J.; Li, J.; Zhang, N.; Hong, R.R.; Deng, X.C.; Tang, P.G.; Li, D.Q. Hydrogen sensing properties of Pt-Au bimetallic nanoparticles loaded on $\mathrm{ZnO}$ nanorods. Sens. Actuators B Chem. 2017, 241, 895-903. [CrossRef]

188. Koo, W.T.; Yu, S.; Choi, S.J.; Jang, J.S.; Cheong, J.Y.; Kim, I.D. Nanoscale PdO Catalyst Functionalized $\mathrm{Co}_{3} \mathrm{O}_{4}$ Hollow Nanocages Using MOF Templates for Selective Detection of Acetone Molecules in Exhaled Breath. ACS Appl. Mater. Interfaces 2017, 9, 8201-8210. [CrossRef] [PubMed]

(C) 2017 by the authors. Licensee MDPI, Basel, Switzerland. This article is an open access article distributed under the terms and conditions of the Creative Commons Attribution (CC BY) license (http:/ / creativecommons.org/licenses/by/4.0/). 